\title{
Ag-Cu Colloid Synthesis: Bimetallic Nanoparticle Characterisation and Thermal Treatment
}

\author{
Jiří Sopoušek, ${ }^{1,2}$ Jiří Pinkas, ${ }^{1,2}$ Pavel Brož, ${ }^{1,2}$ Jiří Buršík, ${ }^{3}$ Vít Vykoukal, ${ }^{1}$ David Škoda, ${ }^{1,2}$ \\ Aleš Stýskalík, ${ }^{1,2}$ Ondřej Zobač, ${ }^{1}$ Jan Vřešt'ál, ${ }^{2}$ Aleš Hrdlička, ${ }^{1,2}$ and Jan Šimbera ${ }^{1}$ \\ ${ }^{1}$ Department of Chemistry, Faculty of Science, Masaryk University, Kotlárská 2, 61137 Brno, Czech Republic \\ ${ }^{2}$ Masaryk University, CEITEC MU, Kamenice 5, 62500 Brno, Czech Republic \\ ${ }^{3}$ Institute of Physics of Materials, ASCR, Žižkova 22, 61662 Brno, Czech Republic
}

Correspondence should be addressed to Jiří Sopoušek; sopousek@mail.muni.cz

Received 17 January 2014; Accepted 13 February 2014; Published 8 April 2014

Academic Editor: Amir Kajbafvala

Copyright (C) 2014 Jiří Sopoušek et al. This is an open access article distributed under the Creative Commons Attribution License, which permits unrestricted use, distribution, and reproduction in any medium, provided the original work is properly cited.

The Ag-Cu bimetallic colloidal nanoparticles (NPs) were prepared by solvothermal synthesis from metalloorganic precursors in a mixture of organic solvents. The nanoparticles were characterized by dynamic light scattering (DLS) and small angle Xray scattering (SAXS). The properties of metallic core and organic shell of the nanoparticles were studied by direct inlet probe mass spectrometry (DIP/MS), Knudsen effusion mass spectrometry (KEMS), double-pulse laser-induced breakdown spectroscopy (DPLIBS), and differential scanning calorimetry (DSC). The transmission electron microscopy (TEM) and scanning electron microscopy (SEM) were used for particle characterization before and after thermal analysis. The experiment yielded results that were for $\mathrm{AgCu}$ nanoparticles for the first time. The detected liquidus temperature has been compared with the prediction obtained from calculation of the phase diagram of Ag-Cu nanoalloy. The experimental results show that of near-eutectic composition $\mathrm{AgCu}$ nanoparticles possess the fcc crystal lattice. Surprisingly, spinodal decomposition was not observed inside the AgCu nanoparticles at temperatures up to $230^{\circ} \mathrm{C}$. The depression of the eutectic AgCu melting point was calculated but not observed. The eutectic AgCu microparticles are formed before melting.

\section{Introduction}

The nanomaterial sciences have contributed to solving constantly increasing number of complex problems in the past decades. The same is true in the field of colloidal solutions of inorganic substances including pure metals and their alloys. In the field of colloidal solutions of pure noble metals, a significant progress has been made in the last few years, which allows us to proceed towards more complex systems including bimetallic colloidal nanoparticles.

Working with nanoparticles of base metals in pure state or with their alloys (nanoalloys) is challenging because of their instability in a common laboratory environment (high reactivity, oxidation). For this reason, it is necessary to protect the nanoparticles. Protection is realized by using the surface layer (protective shell) formed by surfactants or adsorbed substances $[1,2]$. The inner core of the nanoparticles is thus shielded from adverse reactions (e.g., from oxidation by atmospheric oxygen) or from mutual particle contacts. Metal nanoparticles must be stored in a liquid to present stable nanodispersion solutions (colloids). For this purpose, especially in aqueous solutions, the use of surfactants forming a shell with surface charge ( $Z$ potential) is advantageous [3].

Colloids of metals are systems, which involve solid nanoobjects that consist of a metallic core surrounded by a protective shell, which have either steric (nonpolar solvents) or electrostatic (polar solvents) stabilization function [4], as well as of ions and neutral molecules. After solvent evaporation we can obtain nanopowders, which have to be stabilized by adsorbed molecules or by other protective coating. The frequently studied colloids are often solutions of nanoparticles of noble metals $(\mathrm{Au}, \mathrm{Ag}$, and $\mathrm{Pt})[5,6]$ or colloids of metal oxide nanopowders $[7,8]$, which are naturally stable in air. 
Robust conventional materials (bulk) formed from oxides, pure metals, and alloys are usually stable systems with well-defined crystallographic structures. The growing importance of surface-free energy and stress with decreasing particle size must be considered. It is possible to observe changes in thermodynamic stability associated with size. Decreasing particle size can induce modification of cell parameters and/or structural transformations [9]. The increased surface/volume ratio leads to observation of many other effects $[10,11]$ and nanoparticles exhibit unique properties, which are not seen in the bulk materials [12]. A typical nanoeffect is the melting point depression (MPD), which was thermodynamically predicted [13] to be the result of increased proportion of surface to volume atoms. This effect is commonly observed for pure metal nanoparticles [14].

Experimental work with nonnoble bimetallic nanoparticles (binary nanoalloys) is challenging for the synthesis but a large application potential is expected. The changes of liquidus temperatures and also in other phase transformations (including reduction of the eutectic temperatures [15]) of nanoalloys occur. Moreover, the properties of binary nanoparticles are closely linked to their chemical composition.

Bimetallic nanoparticles, particularly those with welldefined alloy structures of noble metals, such as Pt-Ru, $\mathrm{Cu}-\mathrm{Pd}, \mathrm{Pt}-\mathrm{Mo}, \mathrm{Pt}-\mathrm{W}, \mathrm{Pt}-\mathrm{Ni}$, and $\mathrm{Au}-\mathrm{Ag}$ provide practical examples of the influence of composition and structure on their catalytic properties [16, 17]. Au-Ag nanoparticles of alloy-type structure exhibit high catalytic activities for low temperature CO oxidation [18] and aerobic oxidation of alcohols [19]. Interesting optical properties are displayed by metal core/metal shell nanoparticles, for example Au@Cu [20] and Au@Ag [21].

The properties and hence the applicability of metallic nanoparticles depend not only on their size but also on the shape that can be controlled by chemical synthesis. Metal nanoparticles have been prepared in various shapes (other than a spherical), such as rods, cubes, and wires, and also in the form of nanocrystals having an unexpected symmetry. The shape of the nanostructure is equally important for controlling different properties [22]. In the case of silver nanoparticles, the pentamerous symmetry was observed, which is prohibited for the bulk materials [23]. Pentamerous symmetry corresponds to the presence of metal nanoparticles in the form of the decahedron $[24,25]$ or icosahedron [26].

Enhanced catalytic activity can be expected for copper. Copper nanoparticles and nanorods were synthesized by thermal decomposition of copper precursors in the presence of surfactants. Colloidal solutions of copper nanoparticles also have strong antifungal [27] and antimicrobial [28] properties, similar to silver [29-31].

The preparation of the $\mathrm{Cu}$ NPs is problematic due to their easy oxidation. However, one can prepare $\mathrm{CuO}[32$, 33] nanoparticles that are of great interest due to their potential applications in a wide variety of areas including electronic and optoelectronic devices. The behavior of bulk alloys of copper and silver is generally well known as they form a eutectic system. Metal core/metal shell (Cu@Ag) microparticles were also prepared for use in soldering [34].
The interaction between Ag NPs and Cu substrate was studied in work $[10,11]$. Very interesting results were obtained also in an experimental study that deals with the properties of Au@Ag@Cu nanoparticles (three-metal core-shell structure) [35].

The Ag-Cu system exhibits a limited mutual solubility of Ag- and Cu-rich phases in solid. Therefore, a special structure of nanoparticles can be expected. Calculations of the Ag$\mathrm{Cu}$ nanoalloy phase diagram of this system were presented in the papers $[36,37]$ but no experimental information on reliability of calculated values is given till now. One of the unresolved issues is what a tendency for $\mathrm{Ag}$ and $\mathrm{Cu}$ to the spinodal decomposition at the nanometer level is.

This work is focused on the Ag-Cu colloid nanoalloy system of near-eutectic composition Ag-28 wt\% Cu. The aim is to synthesize nanoparticles chemically so as to prevent oxidation of the nanoparticles. For this reason, the synthesis in organic solvents in which the solubility of oxygen is negligible was selected. Subsequent characterization is concentrated on the study of both the metallic core and the protective shell, which is supposed to consist of organic molecules. The aim is also to assess the thermal stability of the obtained $\mathrm{AgCu}$ nanoparticles and compare it with theoretical calculation of the $\mathrm{Ag}-\mathrm{Cu}$ nanoalloy phase diagram based on equilibrium thermodynamics.

\section{Synthesis of Ag-Cu Colloid}

The samples of the Ag-Cu nanoalloy colloids were synthesized by chemical solvothermal coreduction of silver acetate and copper acetylacetonate $\mathrm{Cu}(\mathrm{acac})_{2}$ in a particular stoichiometric ratio (metal input equivalent to $\mathrm{Ag}-42$ at $\% \mathrm{Cu}$ in NPs, that is, eutectic composition) in oleylamine and octadecene at $230^{\circ} \mathrm{C}$ under an inert atmosphere of nitrogen.

The molecular precursors were dissolved in oleylamine and this solution was injected into a hot solvent composed of 1-octadecene and oleylamine at $230^{\circ} \mathrm{C}$. As a heating bath, $\mathrm{Sn}-\mathrm{Pb}$ solder was used. In the reaction mixture, the precursor metal cations were reduced at this temperature and formed the Ag-Cu nanoalloy colloid. The product was separated by centrifugation for $20 \mathrm{~min}$ on a Heraeus Labofuge 400 centrifuge usually at $6000 \mathrm{rpm}$. The product was separated by precipitation with methanol, centrifugation for 10-30 min on the same centrifuge at usually $3500 \mathrm{rpm}$, and washing with methanol/hexane solution. The powders were washed to remove organic-soluble residues by three or more cycles of resuspending them in hexane or light petroleum and subsequent centrifugations. Thus the colloidal solution of the $\mathrm{AgCu}$ NPs in hexane was prepared. The colloids were of yellow-brown color (absorption maxima 390-420 nm) and $20 \mathrm{~mL}$ volume, and they typically contained (5-30) $\mathrm{mg}$ of the solid fraction.

The above described synthetic procedure has been repeated many times and tens of $\mathrm{Ag}-\mathrm{Cu}$ colloidal samples were characterized and studied by the methods described in next sections. The order number of synthesis is included in the sample designation (e.g., AgCu43). 

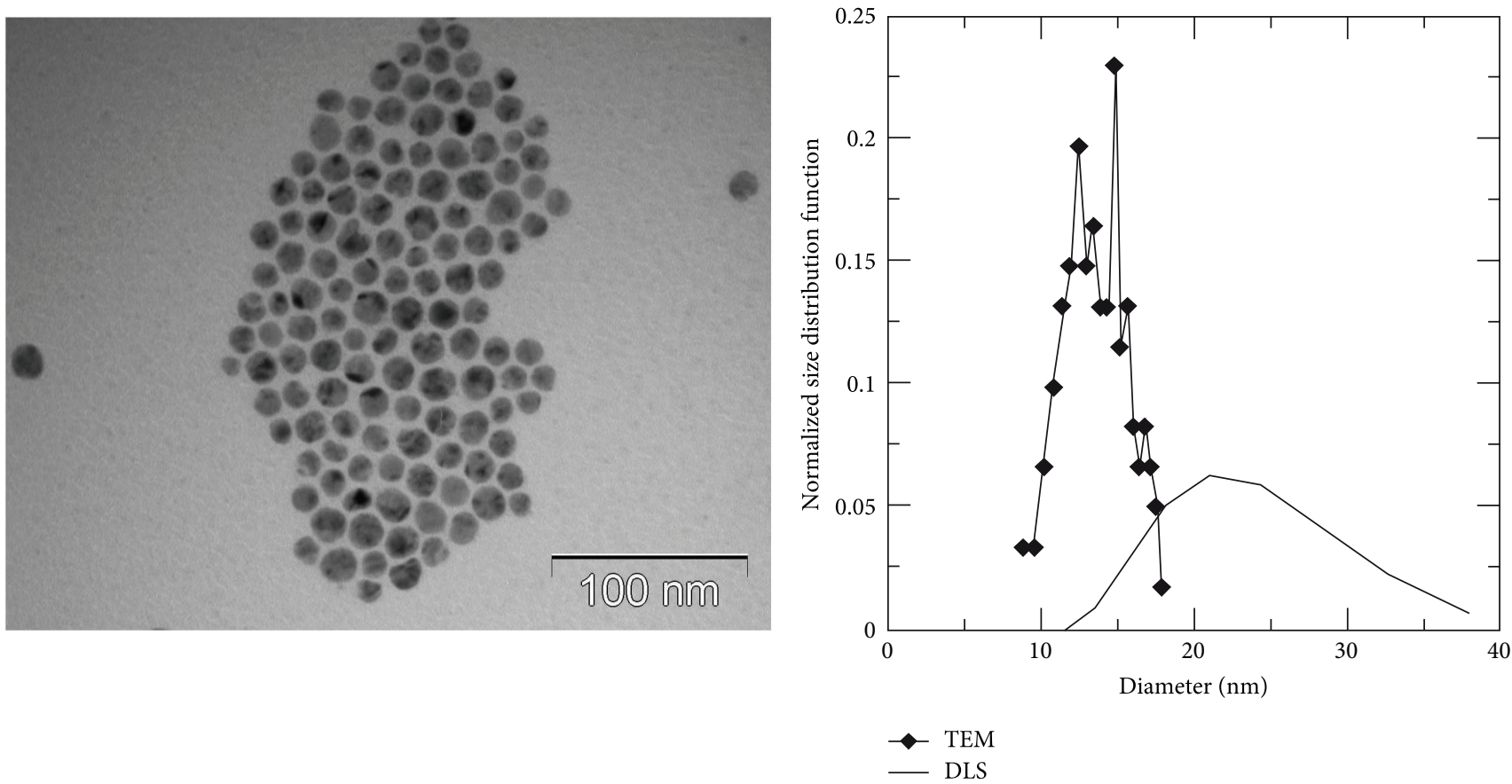

(a)
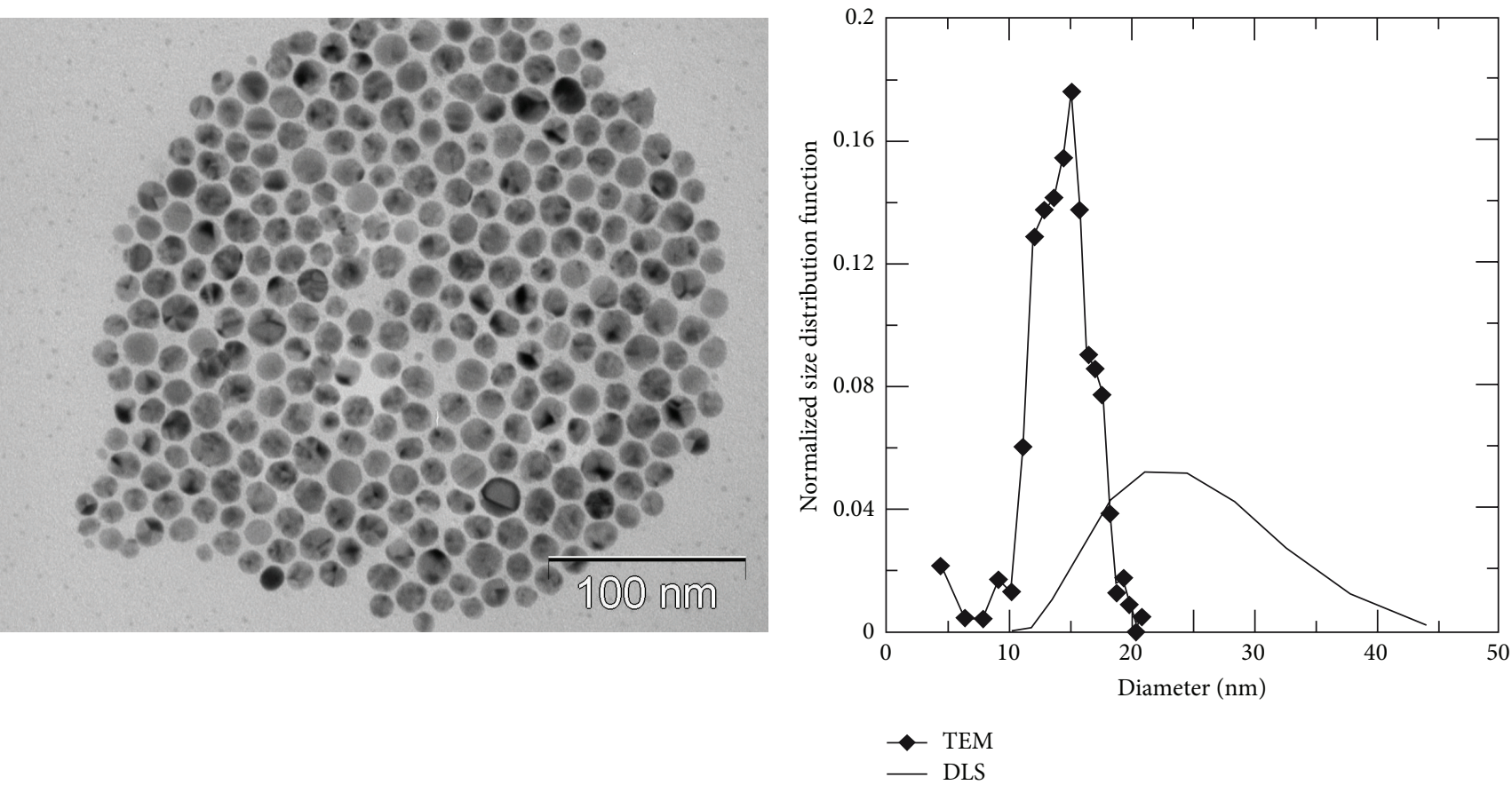

(b)

Figure 1: The particle size distributions of Ag-Cu colloids ((a) sample AgCu43, (b) sample AgCu44); the TEM images (left) and the graphs of distribution measured by DLS and obtained by TEM image analysis (right).

\section{Characterization of Ag-Cu Colloidal Solution}

The colloids of the synthetized nanoparticles were characterized by various techniques: UV-VIS spectroscopy (maximum $420 \mathrm{~nm}$ ), dynamic light scattering (DLS), small-angle X-ray scattering (SAXS), and conventional and high resolution transmission electron microscopy (TEM and HRTEM). The aim was to measure size and shape of the synthetized nanosized particles in organic solvent solution.

The hydrodynamic diameter of the $\mathrm{Ag}-\mathrm{Cu}$ colloidal nanoparticles was measured by the DLS method on a Zetasizer Nano ZS ZEN 3500 DLS instrument at the angle of $173^{\circ}$ in a hexane solution at $25^{\circ} \mathrm{C}$. The results are based 


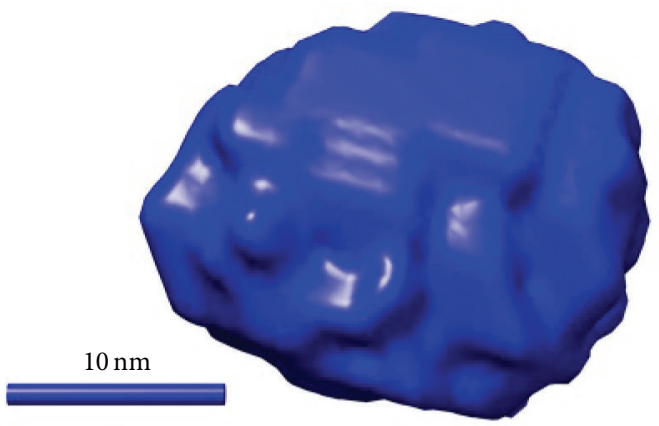

FIGURE 2: The average size and shape of the synthesized nanoparticles Ag-Cu measured by SAXS (sample AgCu36, $23 \mathrm{~nm} / 18 \mathrm{~nm}$ ).

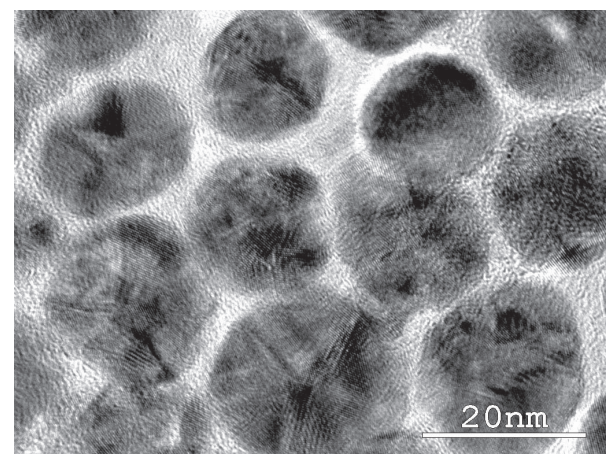

FIgURE 3: The $\mathrm{AgCu}$ multiple twinned nanoparticles (sample AgCu28, HRTEM).

on the intensity of scattered light, with the source being $\mathrm{He}-\mathrm{Ne}$ red laser with a wavelength of $632.8 \mathrm{~nm}$. The DLS measurements were always carried out immediately after the synthesis; some measurements were also carried out at time intervals. A typical measurement result is shown in Figure 1. The measured hydrodynamic average sphere diameters of the nanometer-sized particles of the Ag-Cu colloids immediately after the synthesis were between 20 and $40 \mathrm{~nm}$.

The size and shape of the nanometer-size particles of the Ag-Cu colloids were measured by the SAXS method on a Rigaku BioSAXS-1000 instrument. The results of the SAXS analysis indicate that the nanometer-sized objects in the $\mathrm{Ag}-\mathrm{Cu}$ colloids display an average shape presented in Figure 2. (Sample AgCu36 was prepared from bis(dodecylamino)silver(I) nitrate.) The measurements indicated that the nanometer-sized objects in the colloid samples are of a shape close to sphere or lenticular. The size of these particles was between 20 and $35 \mathrm{~nm}$.

Transmission electron microscopy (TEM) observations were carried out on a Philips CM12 STEM transmission electron microscope operated at $120 \mathrm{kV}$ and a high resolution TEM (HRTEM) JEOL JEM2010 FEG operated at $200 \mathrm{kV}$ with a point resolution of $2.3 \AA$. Both instruments were equipped with an energy dispersive X-ray (EDX) detector. To prepare

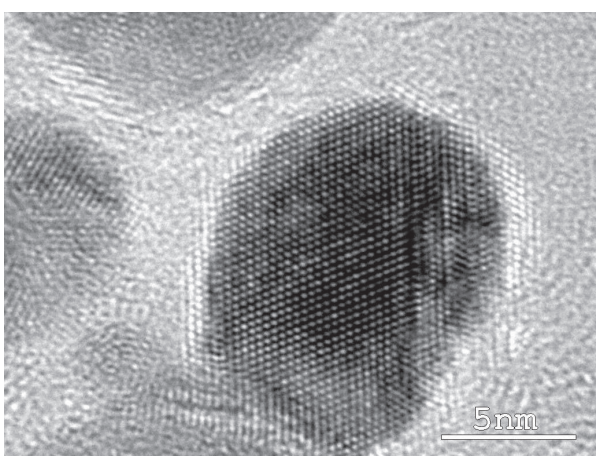

FIgURE 4: Atomic resolution image of a bimetallic nanometer-sized $\mathrm{AgCu}$ particle. (sample AgCu43, HRTEM).

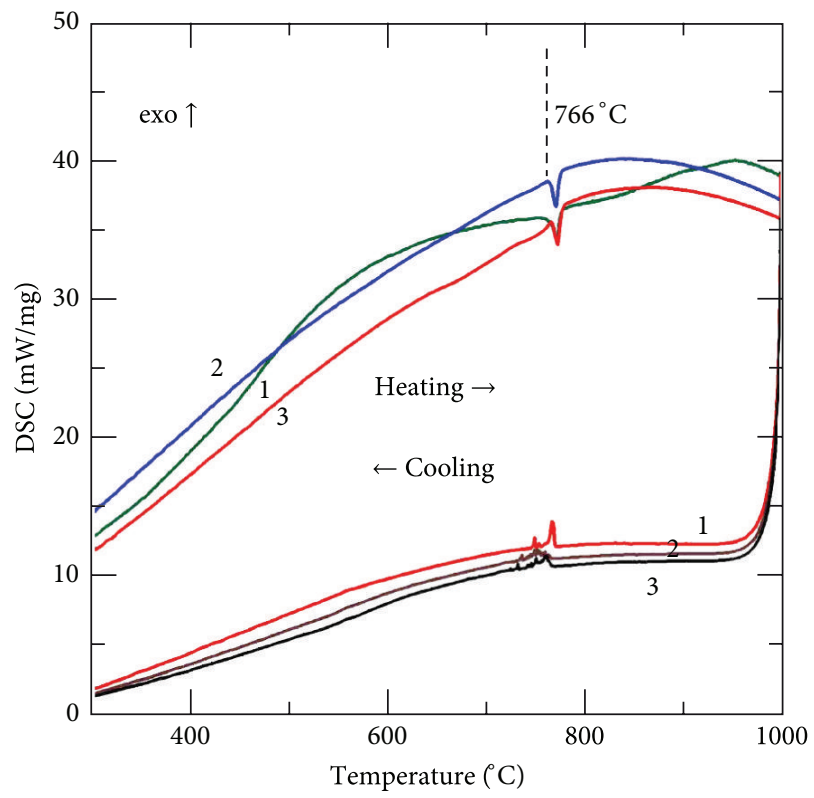

Figure 5: DSC analysis of the AgCu NPs (sample AgCu26, Ag-42 $\mathrm{wt} \% \mathrm{Cu}$ ). The first heating curve is green, the second is blue, and the third is red.

samples for TEM, a drop of dilute Ag-Cu colloid suspension was placed on a carbon-coated grid and allowed to dry by evaporation at ambient temperature.

Both TEM and HRTEM results display only the $\mathrm{AgCu}$ metallic core of the nanoparticles. The solvent/protective organic shell is a subject of evaporation and/or destruction due to vacuum inside the microscope and in addition the method is less sensitive to light elements $(\mathrm{C}, \mathrm{H}, \mathrm{O}$, and $\mathrm{N})$, which constitute the shell. Detailed TEM and HRTEM images of the metallic core of the $\mathrm{AgCu}$ nanoparticles are shown in Figures 3 and 4. The size distributions of the metallic cores given in Figure 1 are consistent with the distribution in Figure 3.

If we look at Figure 3 in detail, it can be seen (HRTEM, the big particle at the bottom) that the metallic cores are not strictly spherical but they are bounded by crystal planes. Bigger particles are often multiply twinned [1] and in some cases it is possible to discern seemingly pentamerous symmetry 


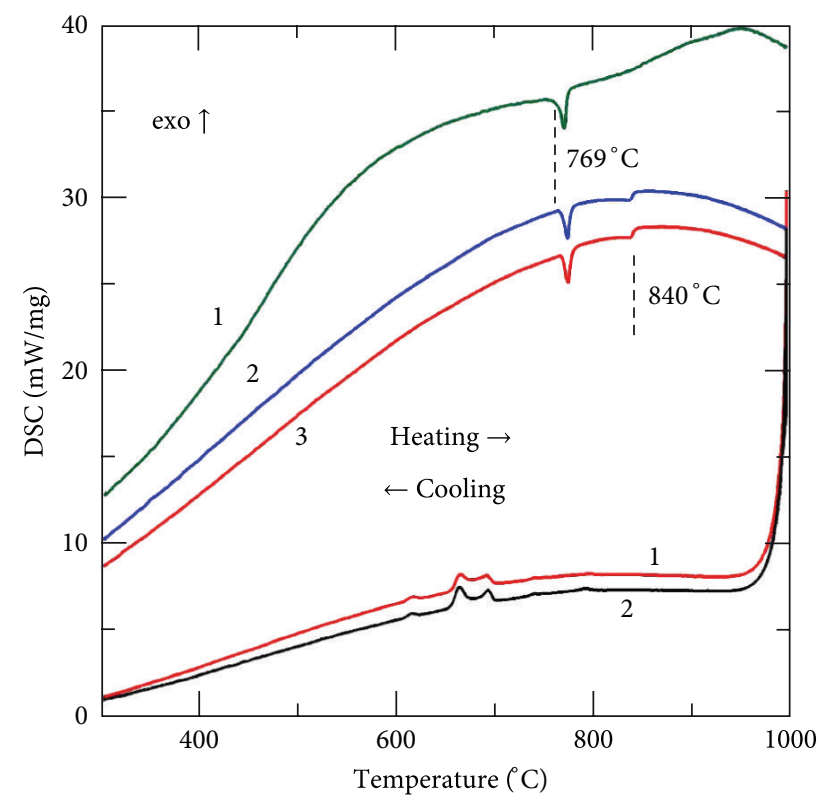

FIgURE 6: DSC analysis of the AgCu NPs (sample AgCu27). The first heating curve is green, the second is blue, and the third is red.

that has been observed also for different nanomaterials by other authors $[25,26]$. The averaged diameters of the metallic cores obtained from TEM of AgCu were (15-25) nm. The high resolution image of a small particle in Figure 4 confirms the expected face-centred cubic crystal lattice.

\section{Characterization of AgCu Nanoparticles}

Our further investigation of the $\mathrm{AgCu}$ nanoparticles ( $\mathrm{AgCu}$ $\mathrm{NPs}$ ) was aimed at both the $\mathrm{AgCu}$ metallic core and the protective shell formed by organic compounds. For this reason two methods were used, namely, differential scanning calorimetry (DSC) and mass spectrometry (MS).

4.1. AgCu Metallic Core Investigation. Thermal properties of the $\mathrm{Ag}-\mathrm{Cu} \mathrm{NPs}$ were investigated by simultaneous thermal analysis (STA) involving DSC. The experiments were carried out on a Netzsch STA 409 CD/3/403/5/G apparatus, a specially-adapted type of the commercial STA 409 CDQMS 403/5 Skimmer Coupling instrument [38] under flowing $\left(70 \mathrm{~cm}^{3} \mathrm{~min}^{-1}\right)$ of pure $(6 \mathrm{~N})$ argon with the heating rate of $10^{\circ} \mathrm{C} \mathrm{min}^{-1}$ from room temperature to $1250^{\circ} \mathrm{C}$. The samples (approximately $10 \mathrm{mg}$ ) were contained in $\mathrm{Y}_{2} \mathrm{O}_{3}$ coated alumina crucibles covered with a lid. The oxygenfree atmosphere was maintained by a metallic zirconium trap located in the hot zone of the calorimeter. This equipment allows theoretical reduction of the oxygen content in the flowing gas in the furnace to a partial equilibrium oxygen pressure above $\mathrm{ZrO}_{2}$ oxide (at real conditions to a partial pressure equivalent to $9 \mathrm{~N}$ inert gas at $1000^{\circ} \mathrm{C}$ ). In other words, oxygen was removed from the inert gas. This is important because, among other things, oxygen affects the melting point of pure Ag. The tabulated melting point of Ag is shifted by

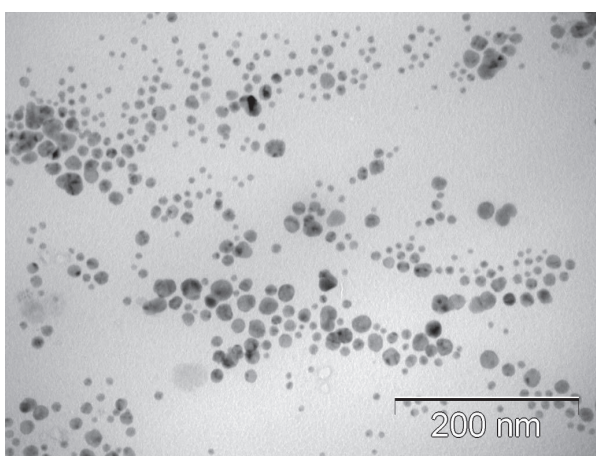

FIgURE 7: TEM image of synthesized nanoparticles Ag-Cu before DSC measurement (sample AgCu26).

$9.1^{\circ} \mathrm{C}$ in air (see Netzsch STA 409 manual for calibration procedure [39]). A similar effect is present for copper and very likely also for the $\mathrm{Ag}-\mathrm{Cu}$ bulk alloy. Thus, the eutectic temperature $779^{\circ} \mathrm{C}$ (eutectic composition $\mathrm{Ag}-28.1 \mathrm{wt} \% \mathrm{Cu}$ ) for bulk $\mathrm{Ag}-\mathrm{Cu}[40]$ is uncertain and may be shifted during the DSC measurement.

Two examples of measured DSC signals of AgCu NPs from cyclic heating and cooling are shown in Figure 5 (sample AgCu26) and Figure 6 (sample AgCu27).

The DSC signal of sample AgCu26 in Figure 5 reveals the thermal behavior of the eutectic bulk alloy. The nanoparticle melting point depression (MPD) (calculated in Section 5) in the first heating sequence was not experimentally observed because the AgCu NPs form bulk microsized particles somewhere at temperatures below the first melting. The absence of MPD was observed in all our DSC experiments. Some samples reveal a small eutectic signal only. A few samples reveal surprisingly no signal as if the nanoparticles were lost. The reason will be explained in discussion (Section 6).

The DSC signal in Figure 6 (sample AgCu27) reveal an exemplary shape for the bulk Ag-Cu hypoeutectic alloy at the second and third remelting. The first heating onset at $769.2^{\circ} \mathrm{C}$ in Figure 6 agrees reasonably with the tabulated $\mathrm{Ag}-\mathrm{Cu}$ eutectic temperature of $779^{\circ} \mathrm{C}$. When the sample undergoes the second and third heating, we can detect an extra signal at $840^{\circ} \mathrm{C}$. The occurrence of the combined signal at $840^{\circ} \mathrm{C}$ and $779^{\circ} \mathrm{C}$ is typical for cases of hyper- or hypoeutectic Ag$\mathrm{Cu}$ alloys. Conversely, the absence of signal at $840^{\circ} \mathrm{C}$ and maintaining signal at $780^{\circ} \mathrm{C}$ is a confirmation of the eutectic composition of the alloys at the start of the DSC experiment. This difference indicates that the alloy composition changes during the analysis from eutectic to noneutectic.

Transmission electron microscopy (TEM) and scanning electron microscopy (SEM) were used for morphology study of the $\mathrm{AgCu}$ NPs before and after the thermal treatment in the differential scanning calorimeter (DSC). The TEM image of synthesized $\mathrm{AgCu}$ nanoparticles (sample $\mathrm{AgCu} 26$ ) before the DSC measurement is in Figure 7. The situation after DSC analysis was investigated by a TESCAN LYRA $3 \mathrm{XMU}$ FEG/SEM $\times$ FIB scanning electron microscope (SEM). The result after repeated heating and cooling during DSC measurement is in Figure 8. Moreover, we can see that 


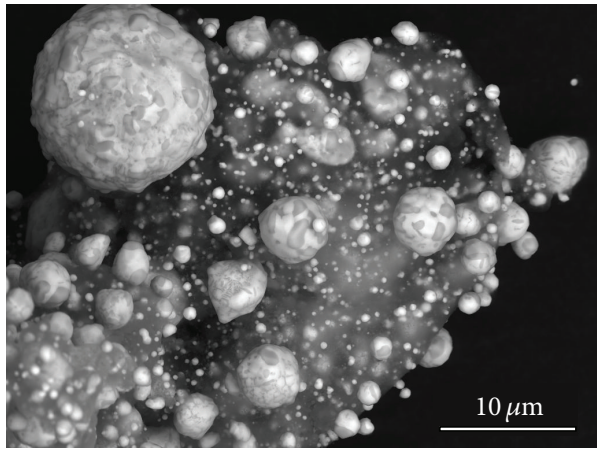

(a)

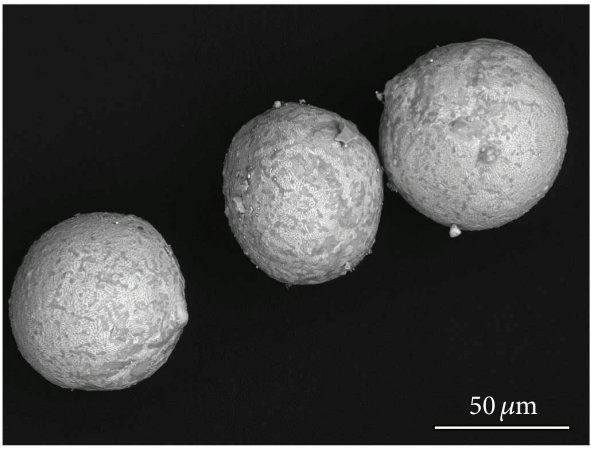

(b)

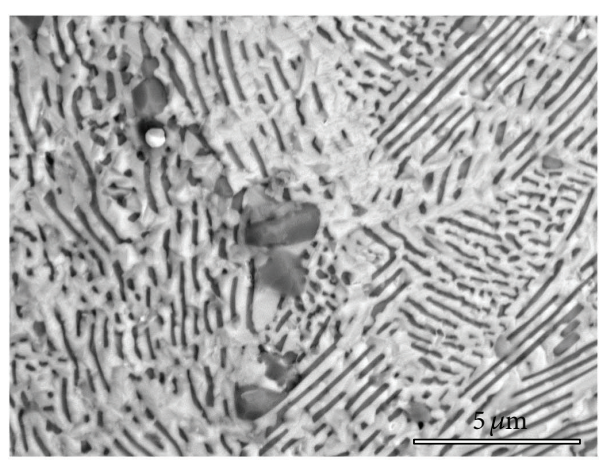

(c)

FIgURE 8: SEM images of synthesized nanoparticles Ag-Cu after DSC measurement (sample AgCu26).

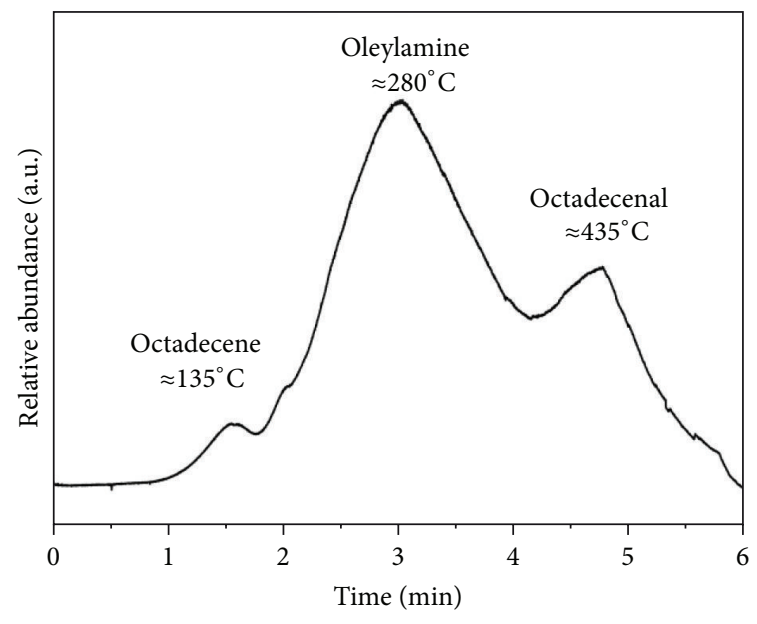

Figure 9: DIP/MS thermogram of the AgCu nanoparticles (heating from $30^{\circ} \mathrm{C}$ up to $450^{\circ} \mathrm{C}$ with heating rate $100^{\circ} \mathrm{C} \mathrm{min}^{-1}$ ).

the AgCu NPs sample after DSC consists of black carbonized powder decorated with metallic spheres (the bulk Ag-Cu eutectic alloy has a color close to gold).

The AgCu nanoparticles before DSC in Figure 7 reveal clearly that the situation is consistent with Figure 3 (sample AgCu43). A completely different view is seen after DSC in Figure 8 that clearly shows the microsized balls with typical phase constitution of a fine Ag-Cu eutectic alloy. The EDX microanalysis identifies an average metal composition of Ag$42 \mathrm{wt} \% \mathrm{Cu}$ (sample AgCu26). The composition of the phases was Ag-65 wt $\% \mathrm{Cu}$ (grey regions) and Ag-10 wt $\% \mathrm{Cu}$ (white regions). It should be noted that analyses of thinner grey regions were inevitably more affected by the presence of surrounding Ag-rich phase. The equilibrium Ag-Cu phase diagram [40] reveals a phase composition (Ag-92.0 wt\% Cu and $\mathrm{Ag}-8.8 \mathrm{wt} \% \mathrm{Cu}$ ) at the eutectic temperature of $779^{\circ} \mathrm{C}$.

The inductively-coupled plasma atomic emission spectroscopy (ICP-OES) analysis of micron-sized particles was performed after the DSC measurements. In all cases, a lower copper content with respect to the starting composition of the nanoparticles was observed.

4.2. Organic Shell Investigation. To understand the degradation changes during heating of the $\mathrm{AgCu} \mathrm{NPs}$, direct inlet probe mass spectrometry (DIP/MS) was used. In this procedure, performed on a TSQ Quantum XLS (Thermo Scientific) instrument equipped with a NIST 11 spectral library, the samples were quickly heated from $30^{\circ} \mathrm{C}$ to $450^{\circ} \mathrm{C}$ with the dwell time at the starting temperature for $30 \mathrm{~s}$ and at the final temperature for $60 \mathrm{~s}$ with the heating rate $100^{\circ} \mathrm{C} \mathrm{min}^{-1}$ and mass spectral information regularly acquired after ionization at electron energy of $70 \mathrm{eV}$ every $1 \mathrm{~s}$. The resulting thermogram complemented with information on the respective organic compounds is shown in Figure 9, 


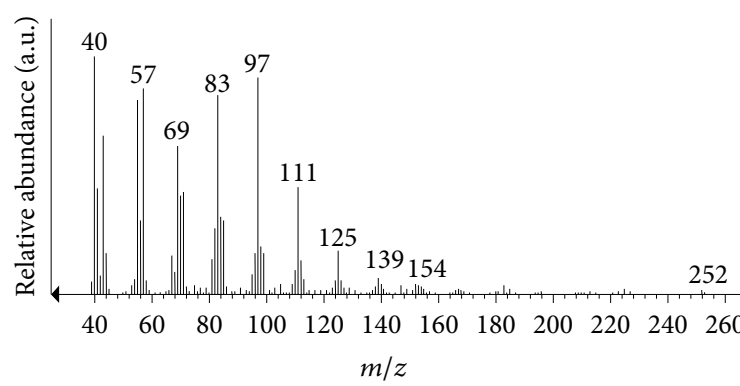

(a)

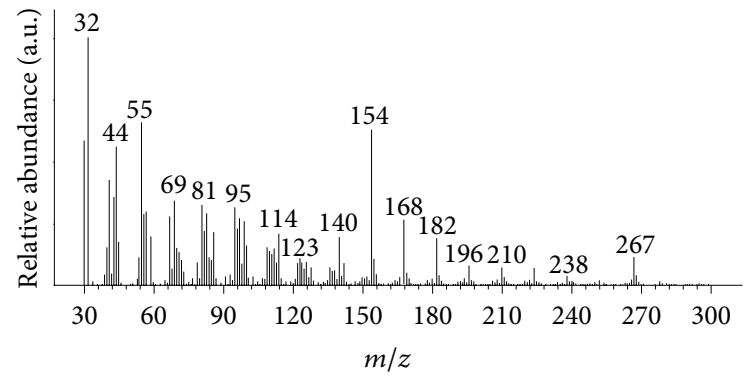

(b)

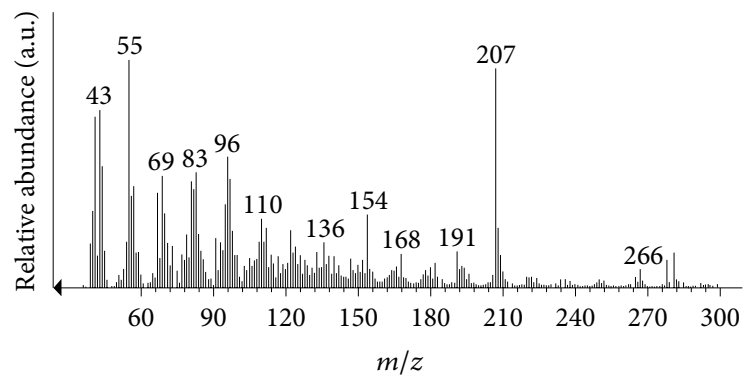

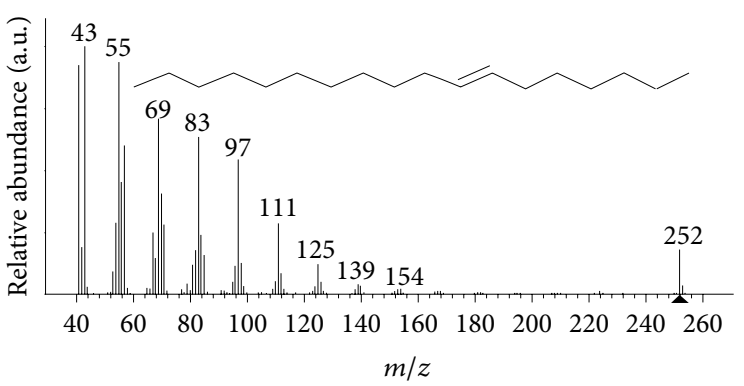
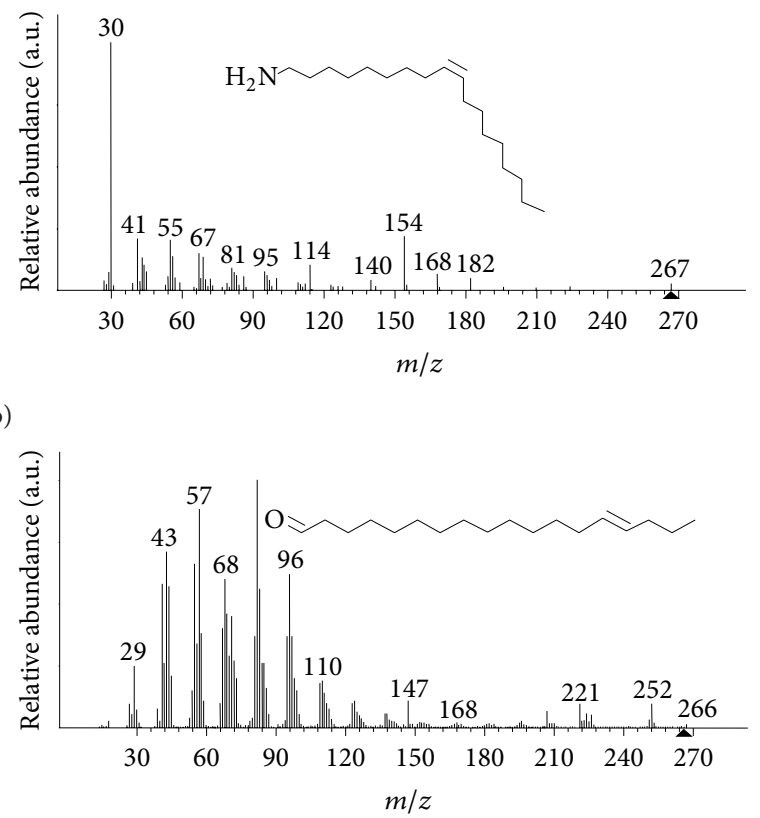

(c)

FIgURE 10: Mass spectra of (a) octadecene, (b) oleylamine, and (c) octadecenal acquired during DIP/MS measurement on the AgCu NPs and tabulated in the NIST 11 mass spectral database.

whereas the comparison of the acquired mass spectra with the tabulated ones from the NIST 11 spectral database is shown in Figure 10.

As the results from these measurements indicate, the surface effects on the alloy nanoparticles caused by the organic compounds can be expected. For a more detailed understanding of the phenomena, Knudsen effusion mass spectrometric (KEMS) measurements using a Netzsch STA 409 instrument (specified already in Section 4.1) were performed. In this case, the samples underwent slow heating and cooling process at conditions consistent with the DSC measurement (heating from 30 to $940^{\circ} \mathrm{C}$ with the heating rate of $5^{\circ} \mathrm{C} \mathrm{min}^{-1}$ ) and the mass spectra were recorded within each $40 \mathrm{~s}$. As follows from Figure 11, the expected organic compounds are still detectable at temperatures much higher than their tabulated boiling temperatures $\left(\sim 500^{\circ} \mathrm{C}\right)$.

This finding indicates a surface reaction of organic compounds with the alloy nanoparticles which is also supported by the fact that after the heating a pink thin coating was observed in the Knudsen cell around the inner small alumina crucible in which the sample was placed while the remaining sample in the alumina crucible was grey (see Figure 12).

A chemical analysis by double-pulse laser-induced breakdown spectroscopy (DPLIBS) showed the pink coating to be rich in copper and the remaining black sample in silver. The respective spectra are shown in Figure 13.

The mass transfer of copper-containing substances from the alumina crucible and $\mathrm{Cu}$ deposition in the Knudsen cell (see Figure 12) indicate copper form organic compound(s) which is deposited at colder places. Thus, the chemical composition of the $\mathrm{AgCu}$ nanoparticles is changing to a higher Ag content during heating as copper is leaving the AgCu NPs sample.

\section{Calculation of Ag-Cu Nanoalloy Phase Diagram}

The surface-to-volume ratio increases with decreasing nanoparticle size and brings therefore a substantial contribution of the surface energy to the Gibbs energy in thermodynamic 


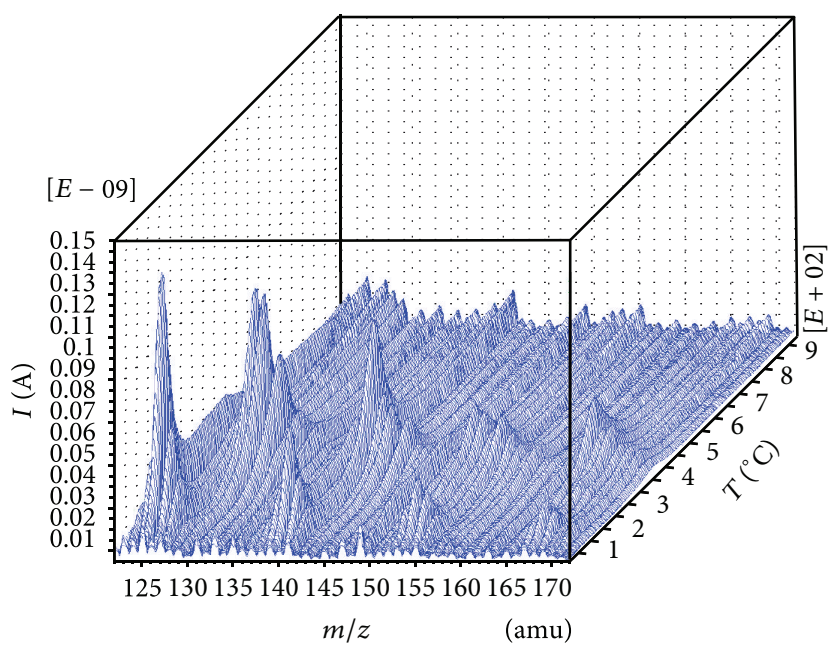

(a)

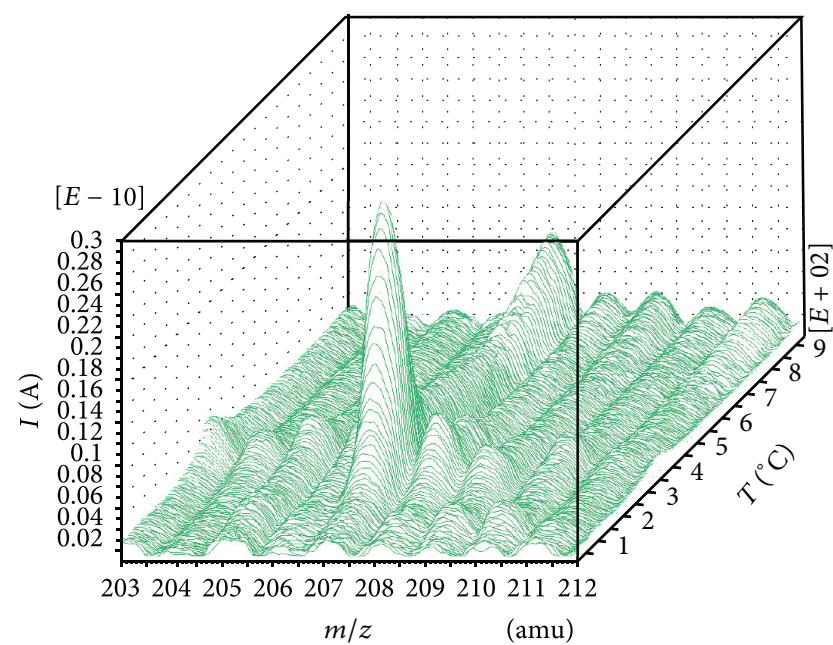

(b)

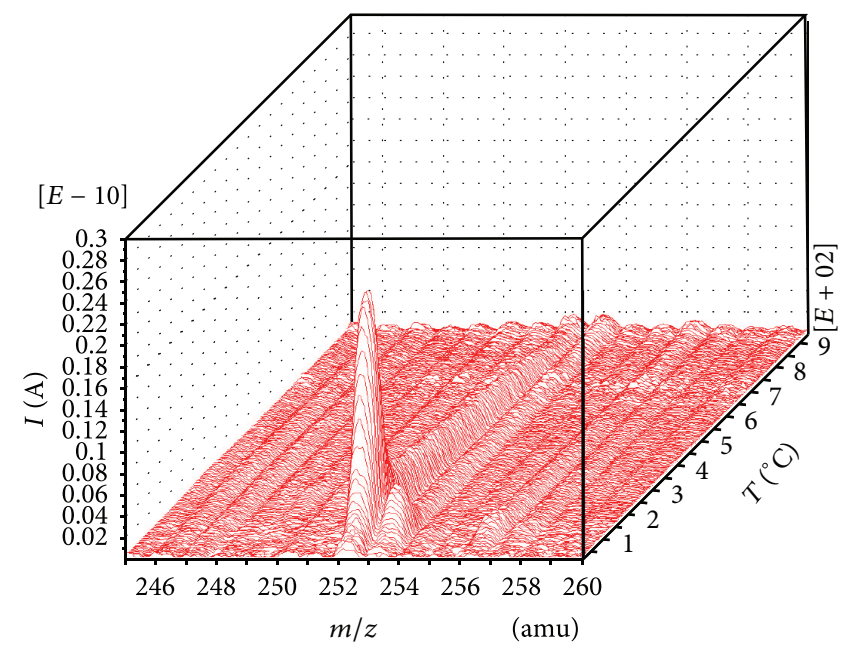

(c)

FIGURE 11: Selected parts of mass spectral data acquired during KEMS heating of nano $\mathrm{Ag}$-Cu, (heating from 30 to $940^{\circ} \mathrm{C}$ with the heating rate of $5^{\circ} \mathrm{C} \mathrm{min}{ }^{-1}$ ), consistent with DSC temperature program, showing masses typical for octadecenes, oleylamine, and octadecenals.

considerations. The contribution of the surface energy to the total Gibbs energy of the particles with dimensions 5-100 nm can be thermodynamically estimated by coupling of surface contribution to the Gibbs energy of phase in the CALPHAD approach.

The method presented by Park and Lee [13], which is based on the minimization of the molar Gibbs energy of the entire system represented by the sum of the molar Gibbs energy of the phases occurred in the system, is used in this work for calculation of the phase diagram of the $\mathrm{Ag}-\mathrm{Cu}$ system in the CALPHAD method. The Gibbs energy of a phase (liquid or solid) is given by

$$
G=G^{\text {Bulk }}+G^{S}
$$

where $G^{\text {Bulk }}$ is the Gibbs energy of the phase in form of bulk binary alloy and $G^{S}$ means the surface Gibbs energy contribution of nanoparticles.
The Gibbs energy of the bulk $G^{\text {Bulk }}$ is expressed by the standard CALPHAD way

$$
\begin{aligned}
G^{\text {Bulk }}= & x_{A}^{0} G_{A}+x_{B}^{0} G_{B} \\
& +R T\left(x_{A} \ln x_{A}+x_{B} \ln x_{B}\right)+G^{E, \text { Bulk }},
\end{aligned}
$$

where $x_{A}$ and $x_{B}$ are molar fractions of components $A$ (i.e., $\mathrm{Ag}$ ) and $B$ (i.e., $\mathrm{Cu}$ ), ${ }^{0} G_{A}$ and ${ }^{0} G_{B}$ are standard Gibbs energies of $A$ and $B$ in the given phase [41], $R$ is the gas constant, and $T$ is the temperature. $G^{E \text {,Bulk }}$ is the excess Gibbs energy of the bulk of phase, expressed usually by the Redlich-Kister polynomial

$$
G^{E, \text { Bulk }}=x_{A} x_{B} \sum_{n} L^{n}(T) \cdot\left(x_{B}-x_{A}\right)^{n},
$$

where $n=0,1,2, \ldots$ and parameters $L^{n}(T)$ are temperature dependent. Consider

$$
L^{n}(T)=a_{n}+b_{n} \cdot T+c_{n} \cdot T \cdot \ln (T) .
$$




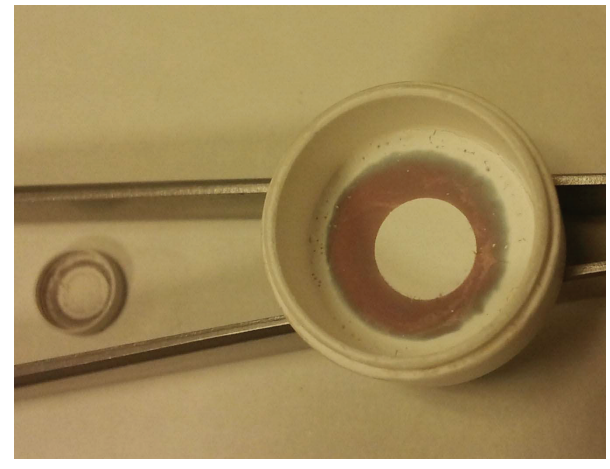

FIGURE 12: Knudsen cell (right) and inner alumina crucible (left) after KEMS measurement of the $\mathrm{AgCu}$ nanoparticles with a pink "organometallic" coating (rich in $\mathrm{Cu}$ ) and a grey powder (rich in $\mathrm{Ag}$ ).

The temperature dependent parameters $L^{n}(T)$ can be extracted from a thermodynamic database [40].

The Gibbs energy of the surface $G^{S}$ of phase is expressed for isotropic spherical particles by

$$
G^{S}=\frac{2 C \tau V}{r},
$$

where $\tau$ is the surface tension, $V$ is the molar volume, $r$ is the radius of the particle, and $C$ is the correction factor considering effects from the shape, the surface strain due to nonuniformity, and the uncertainty of the surface tension measurements [42]. The value of $C$ for an fcc solid structure as well as for a liquid was estimated to be 1.00 [42].

Input data for the calculation of surface tension and molar volume needed for Gibbs energy of the surface $G^{S}$ evaluation for the Ag-Cu system are summarized in Appendix A. With respect to limited mutual solubility (maximum 10 at\%) of these components in a solid fcc-phase, only the concentration dependence of surface tension in liquid phase was calculated by the Butler equation [43,44]. The result is given in Figure 14.

The Gibbs energies of the bulk $G^{\text {Bulk }}$ for liquid and solid (fcc) phases consisting of $\mathrm{Ag}$ and $\mathrm{Cu}$ species were calculated using thermodynamic description based on input data for the Ag-Cu binary alloy given in Appendix B. Details of the calculation are described for the case of $\mathrm{CuNi}$ nanoparticles by Sopousek et al. [45].

The Gibbs energy of the surface $G^{S}$ and Gibbs energies of the bulk $G^{\text {Bulk }}$ were summed (see (1)) for liquid as well as for solid ( $\mathrm{fcc}$ ) phases. The phase energies involving surface contribution were treated by a standard way using CALPHAD method applying ThermoCalc software [46]. The resulting phase diagram for the $\mathrm{Ag}-\mathrm{Cu}$ nanoalloy is presented in Figure 15. The phase boundaries were calculated for a diameter of $20 \mathrm{~nm}$ (i.e., $1 / r=110^{8} \mathrm{~m}^{-1}$ ) and they are compared with the phase diagram for conventional (bulk) Ag-Cu alloy $(1 / r=0)$.

\section{Discussion of Results}

Solvothermal synthesis was used for the sample preparation of the Ag-Cu bimetallic colloids. We managed to prepare samples suitable for further characterization and analysis. The yield of the synthesis was limited. The preparation of large quantities would not lead to a good dispersion of nanoparticles. The isolated yield was also affected by purifying samples via centrifugation and decantation. The intention was to prepare the nanoparticles with eutectic composition. The stability of the obtained colloid was sufficient for the subsequent use of samples for further characterization.

The obtained colloidal samples were transferred into hexane and characterized by various methods. By comparing the size distribution of the nanoparticles obtained by the TEM and DLS methods (see Figure 1), it was found that the hydrodynamic diameter of nanoparticles is about $45 \%$ larger than the radius of the core (i.e., the difference of the radii of about $3.5 \mathrm{~nm}$ ). This great difference indicates that also in the nonpolar medium there is the stabilizing shell composed of several layers of organic molecules. This hypothesis is also supported by SAXS measurements (Figure 2). Moreover, SAXS indicates a slight preference for lenticular shape of the $\mathrm{AgCu}$ nanoparticles.

The pentamerous symmetries were found in some particles via HRTEM (Figure 3). It is possible to consider the $\mathrm{AgCu}$ nanoparticles giving priority to the shape of decahedron. This shape can explain the lenticular models offered by SAXS.

The atomic arrangements inside individual nanoparticles were also studied by HRTEM (see Figure 4). The segregation of $\mathrm{Ag}$ from $\mathrm{Cu}$, which occurred for the equilibrated bulk Ag$\mathrm{Cu}$ alloy (Figures 8(c) and 15), was excluded in nanoparticles produced at $230^{\circ} \mathrm{C}$. Simultaneously, it was confirmed that $\mathrm{Ag}$ and $\mathrm{Cu}$ form a substitutional solid solution with the face centered cubic lattice. The disturbances in the crystal lattice are boundaries of twin crystals (twins). No oxides were observed on the $\mathrm{AgCu}$ nanoparticle surface. This confirms that the thermal synthesis in organic solvent with a minimum solubility of oxygen is a suitable method for the preparation of oxide-free metallic nanoparticles.

An experiment has also dealt with the thermal behavior of nanoparticles at gradually increasing temperature. The $\mathrm{AgCu}$ metallic core was examined by DSC. Behavior of stabilizing protective shell was monitored by mass spectrometry.

By DSC method, it was found that the $\mathrm{AgCu}$ nanoparticles do not show the melting point depression. The eutectic melting point of the $\mathrm{AgCu}$ bulk (Figure 6) and the DSC signal of bulk $\mathrm{Ag}-\mathrm{Cu}$ alloy having no eutectic composition (Figure 5) were detected. All together, the changes of the DSC signals of samples during the heat treatments and the chemical analyses of the samples after DSC by the ICPOES method show that there are changes in the chemical composition of nanoparticles accompanied by a loss of copper from the samples. The changes in the concentration of $\mathrm{Cu}$ cannot be explained by increased evaporation of $\mathrm{Cu}$, because the vapor pressure of $\mathrm{Cu}$ and $\mathrm{Ag}$ is negligible at the monitored temperatures even if we allow discretion of the Kelvin equation. 


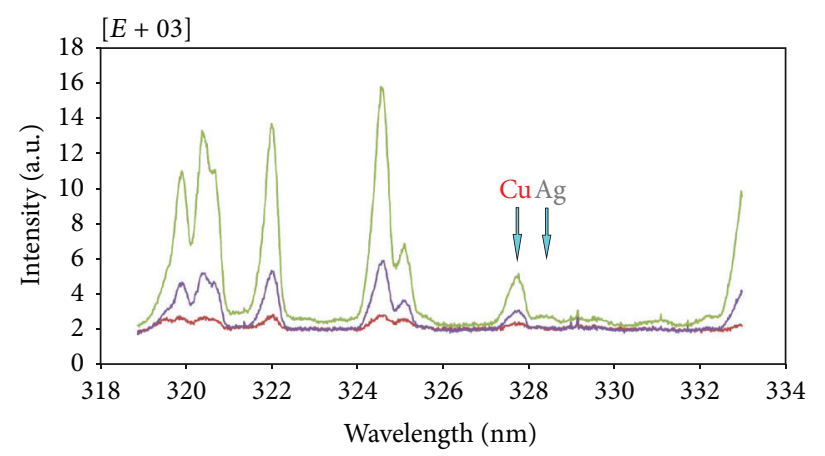

(a)

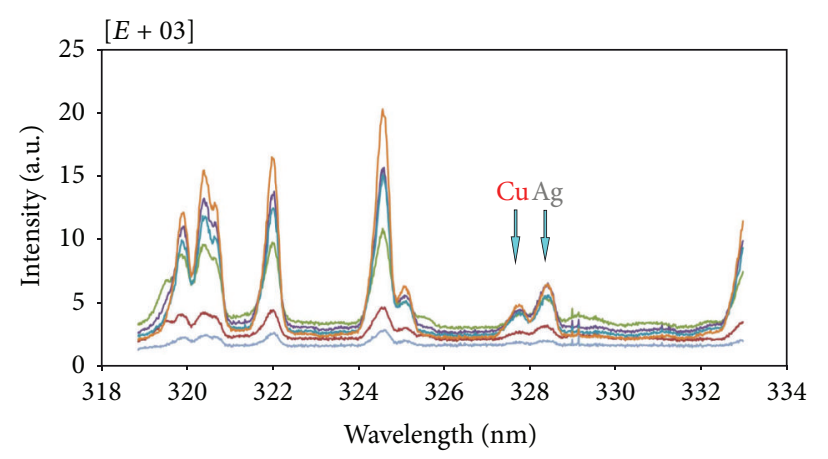

(b)

FIGURE 13: DPLIBS analysis of the inner surface of (a) Knudsen cell and (b) $\mathrm{Al}_{2} \mathrm{O}_{3}$ crucible after KEMS measurement of the AgCu NPs.

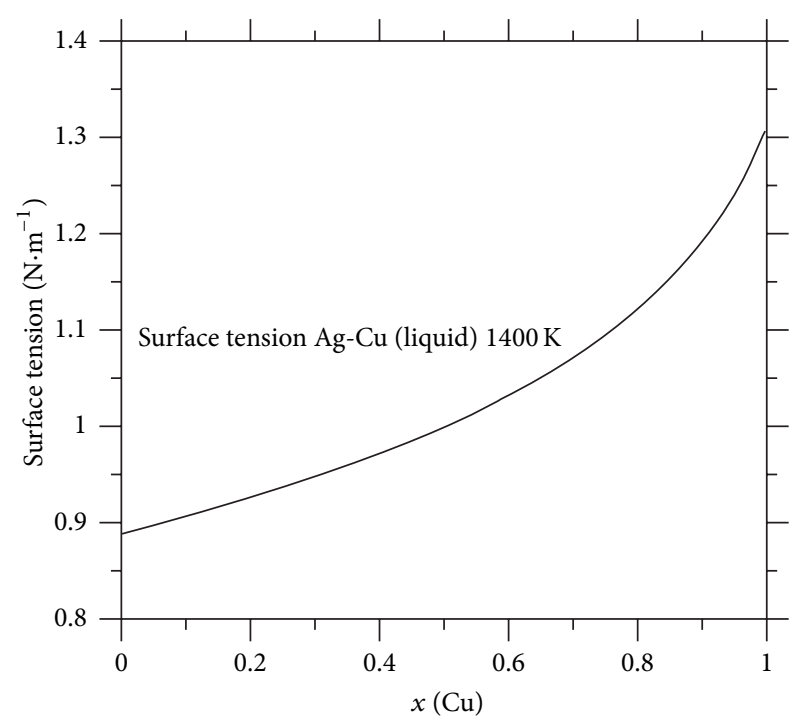

FIGURE 14: Concentration dependence of surface tension (surface energy) for liquid phase in the $\mathrm{Ag}-\mathrm{Cu}$ system at $1400 \mathrm{~K}$ calculated by the Butler equation.

The final stage of the thermal treating of the Ag-Cu NPs is a compact eutectic bulk alloy (Figure 8). Organic molecules carbonize during heating to high temperatures $\left(1000^{\circ} \mathrm{C}\right)$ and they create a carbon-rich residue, which is visible in Figure 8 (top micrograph).

The DIP mass spectrometry showed important information about what is released from the stabilization shell of $\mathrm{AgCu}$ NPs with increasing temperature. During this experiment, nanoparticles are heated at high speed (about $100 \mathrm{~K} / \mathrm{min}$ ) to $450^{\circ} \mathrm{C}$. The DIP/MS thermogram (Figure 9) demonstrates that increasing temperature gives rise to removal of organic molecules (successively: 7-octadecene, oleylamine, and 14-octadecenal), which are related to the composition of the reaction mixture in the synthesis of $\mathrm{Ag}$ $\mathrm{Cu}$ colloid. At the highest temperatures, the MS spectrum of outgoing substances corresponds to 14-octadecenal with a large signal at $207 \mathrm{~m} / \mathrm{z}$.

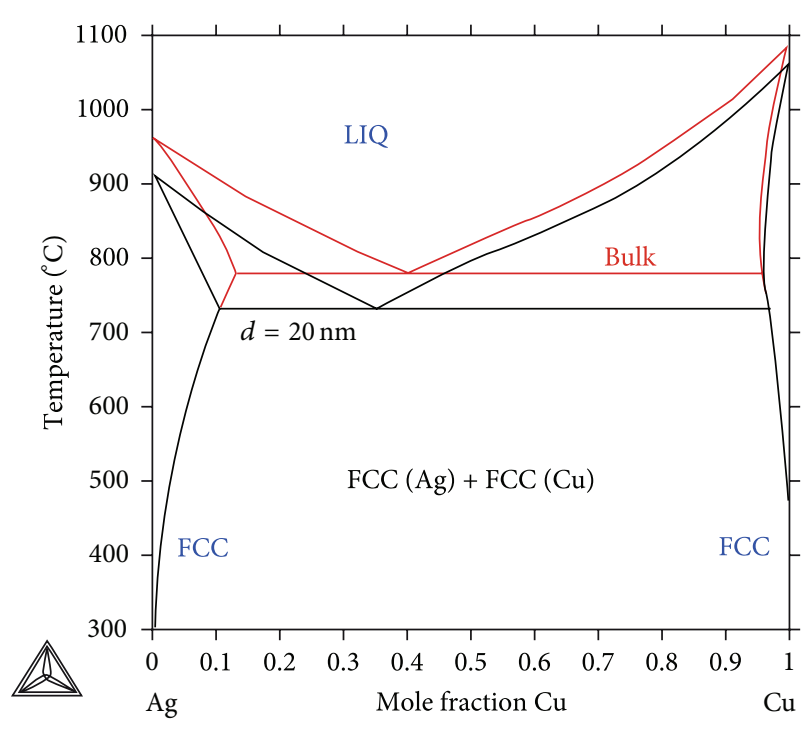

FIgURE 15: The phase diagram of the Ag-Cu system for bulk alloys (red) and for nanoalloys of diameter $20 \mathrm{~nm}$.

The experiment of heating of the AgCu NPs with stabilizing shell was repeated with a higher accuracy by the Knudsen effusion mass spectrometry (KEMS) at defined slow heating rate of $5 \mathrm{~K} / \mathrm{min}$ and the maximum temperature about $1000^{\circ} \mathrm{C}$. The MS spectra given in Figure 11. were observed. An important finding was that the signals of fragments of organic molecules were detected at temperatures well above $450^{\circ} \mathrm{C}$. In particular, the peak at $207 \mathrm{~m} / \mathrm{z}$ (see Figure 11) is detected with the maximum intensity at the temperature of $420^{\circ} \mathrm{C}$ (in agreement with DIP/MS in Figure 9) and later increases at temperatures close to the highest temperature of $940^{\circ} \mathrm{C}$. The explanation for this effect is that the organic fragments are generated during deposition of $\mathrm{Cu}$ inside the Knudsen cell (see Figure 12).

The calculation of the phase diagram of $\mathrm{AgCu}$ nanoalloy by the CALPHAD method using surface tension of the bulk $\mathrm{Ag}-\mathrm{Cu}$ alloy in liquid and solid (fcc) states is in the theoretical Section 5 of this paper. The result in Figure 15 demonstrates the shift of the phase boundaries when the sample 
is composed only of spherical $\mathrm{AgCu}$ nanoparticles with a diameter of $20 \mathrm{~nm}$. This calculation does not include the effect of the organic stabilization shell, whose presence on the $\mathrm{AgCu}$ NPs surface has been proven in this work. However, this result allows calculating the temperature depression of the phase transformations for spherical AgCu nanoparticles in a first approximation. From this calculation (Figure 15), it is clear that the eutectic melting temperature of the $\mathrm{Ag}-\mathrm{Cu}$ alloy in the form of bulk is $780^{\circ} \mathrm{C}$ and for $20 \mathrm{~nm}$ nanoparticles is theoretically reduced to $756^{\circ} \mathrm{C}$. This phenomenon was not observed experimentally due to the interaction between the nanoparticles themselves and their surroundings before reaching the melting point.

\section{Conclusion}

(i) The solvothermal synthesis of Ag-Cu colloid and storing of $\mathrm{AgCu}$ nanoparticles in nonpolar hydrocarbons exhibiting negligible solubility of oxygen is a suitable method for the preparation of oxide-uncontaminated samples.

(ii) The investigated $\mathrm{AgCu}$ nanoparticles have the fcc crystal lattice. It is possible that the nanoparticles attain a shape with pentamerous symmetry.

(iii) Spinodal decomposition was not observed inside the $\mathrm{AgCu}$ nanoparticles at temperatures below $230^{\circ} \mathrm{C}$. The reason can be the metastable state of the nanoparticles but there are also other unknown effects at the nanoscale level that hinder the $\mathrm{Cu}$ - and Agrich phase separation. General equilibrium thermodynamics cannot be used to describe this system at these conditions. The eutectic microparticles are formed before melting.

(iv) A spontaneous separation of copper and silver atoms was observed during the heating of the $\mathrm{AgCu}$ nanoparticles under high vacuum. This effect was accompanied by high organic fragment concentrations in MS spectra.

(v) The depression of the eutectic Ag-Cu alloy melting point was calculated but not observed.

\section{Appendices}

\section{A. Table I}

Physical properties of pure Ag and Cu elements (L: liquid and S: solid (i.e., fcc) phases)

Surface Tension in $\left[N \cdot m^{-1}\right]$

Ag [47]:

$$
\begin{aligned}
& \sigma_{s}=1.438-2.2810^{-4} \mathrm{~T}, \\
& \sigma_{l}=1.207-2.2810^{-4} \mathrm{~T} .
\end{aligned}
$$

$\mathrm{Cu}$ (weighted function based on literature sources [47-51]):

$$
\begin{aligned}
& \sigma_{s}=1.9535-2.2610^{-4} \mathrm{~T} \\
& \sigma_{l}=1.6242-2.2610^{-4} \mathrm{~T} .
\end{aligned}
$$

Molar Volume in $\left[\mathrm{m}^{3} \mathrm{~mol}^{-1}\right]$

$$
\begin{aligned}
& \text { Ag [52]: } \\
& V_{s}=1.120710^{-5} \\
& V_{l}=1.019810^{-5}+1.136810^{-9} \mathrm{~T} \text {. }
\end{aligned}
$$

$\mathrm{Cu}:$

$$
\begin{aligned}
& V_{s}=7.0910^{-6} \\
& V_{l}=6.9510^{-6}+8.0810^{-10} \mathrm{~T}
\end{aligned}
$$

\section{B. Table II}

Thermodynamic parameters of pure elements [41] in liquid and solid (fcc) phases and binary excess molar Gibbs energy of bulk Ag-Cu alloy in liquid and solid (fcc) phases [40] complemented by surface energy contribution are dependent on reciprocal radius $1 / r=\mathbf{R} \mathbf{R}$ (see in bold below).

\section{Pure Elements}

PARAMETER G(LIQUID,AG;0) 298.15

$3815.564+\mathbf{2 . 4 6 2 e}-\mathbf{5} * \mathrm{RR}+109.310993 * \mathrm{~T}-\mathbf{1 . 9 0 6 e}$ $-\mathbf{9} * \mathbf{R R} * \mathbf{T}-23.8463314 * \mathrm{~T} * \mathrm{LN}(\mathrm{T})$

$-1.790585 \mathrm{E}-3 * \mathrm{~T} * * 2-\mathbf{5 . 1 8} \mathbf{e}-\mathbf{1 3} * \mathbf{R} \mathbf{R} * \mathbf{T} * * \mathbf{2}-$ $0.398587 \mathrm{E}-6 * \mathrm{~T} * * 3$

$-12011 * \mathrm{~T} * *(-1)-1044.905 \mathrm{E}-23 * \mathrm{~T} * * 7 ; 1234.93 \mathrm{Y}$

$-3587.111+2.462 \mathrm{e}-\mathbf{5} * \mathbf{R R}+180.964656 * \mathrm{~T}-\mathbf{1 . 9 0 6 e}$

$-\mathbf{9} * \mathbf{R R} * \mathbf{T}-33.472 * \mathrm{~T} * \mathrm{LN}(\mathrm{T})$

$-5.18 \mathrm{e}-13 * \mathbf{R R} * \mathrm{~T} * * 2 ; 3000 \mathrm{~N}$ !

PARAMETER G(FCC_A1,AG:VA;0) 298.15

$$
\begin{aligned}
& -7209.512+3.224 \mathbf{e}-\mathbf{5} * \mathbf{R R}+118.202013 * \mathrm{~T}-\mathbf{5 . 1 1 0 4 e} \\
& -\mathbf{9} * \mathbf{R R} * \mathrm{~T}-23.8463314 * \mathrm{~T} * \mathrm{LN}(\mathrm{T}) \\
& -1.790585 \mathrm{E}-3 * \mathrm{~T} * * 2-0.398587 \mathrm{E}-6 * \mathrm{~T} * * 3 \\
& -12011 * \mathrm{~T} *(-1) ; 1234.93 \mathrm{Y} \\
& -15095.252+\mathbf{3 . 2 2 4 e}-\mathbf{5} * \mathbf{R R}+190.266404 * \mathrm{~T} \\
& -\mathbf{5 . 1 1 0 4 e}-\mathbf{9} * \mathbf{R} \mathbf{R} * \mathbf{T}-33.472 * \mathrm{~T} * \mathrm{LN}(\mathrm{T}) \\
& +1411.773 \mathrm{E}+26 * \mathrm{~T} * *(-9) ; 3000 \mathrm{~N} !
\end{aligned}
$$

PARAMETER G(LIQUID,CU;0) 298.15

$$
\begin{aligned}
& 5194.277+\mathbf{2 . 2 5 8 E}-\mathbf{5} * \mathbf{R} \mathbf{R}+120.973331 * \mathrm{~T}-\mathbf{5 . 1 6 6 9} \mathrm{E} \\
& -\mathbf{1 0} * \mathbf{R} \mathbf{R} * \mathbf{T} \\
& -24.112392 * \mathrm{~T} * \mathrm{LN}(\mathrm{T}) \\
& -2.65684 \mathrm{E}-3 * \mathrm{~T} * * 2-\mathbf{3 . 6 5 2 2} \mathrm{E}-\mathbf{1 3} * \mathbf{R R} * \mathrm{~T} * * \mathbf{2}+ \\
& 0.129223 \mathrm{E}-6 * \mathrm{~T} * * 3
\end{aligned}
$$


$+52478 * \mathrm{~T} * *(-1)-584.89 \mathrm{E}-23 * \mathrm{~T} * * 7 ; 1357.77 \mathrm{Y}$

$-46.54+2.258 \mathrm{E}-5 * \mathrm{RR}+173.881484 * \mathrm{~T}-\mathbf{5 . 1 6 6 9 \mathrm { E }}$

$-\mathbf{1 0} * \mathbf{R R} * \mathbf{T}-31.38 * \mathrm{~T} * \mathrm{LN}(\mathrm{T})$

$-3.6522 \mathrm{E}-13 * \mathbf{R R} * \mathrm{~T} * * 2 ; 3200 \mathrm{~N}$ !

PARAMETER G(FCC_A1,CU:VA;0) 298.15

$$
\begin{aligned}
& -7770.458+2.77 \mathrm{E}-\mathbf{5} * \mathbf{R R}+130.485235 * \mathrm{~T}- \\
& \text { 3.2047E }-\mathbf{9} * \mathbf{R R} * \mathbf{T}-24.112392 * \mathrm{~T} * \mathrm{LN}(\mathrm{T}) \\
& -2.65684 \mathrm{E}-3 * \mathrm{~T} * * 2+0.129223 \mathrm{E}-6 * \mathrm{~T} * * 3 \\
& +52478 * \mathrm{~T} * *(-1) ; 1357.77 \mathrm{Y} \\
& -13542.02+\mathbf{2 . 7 7 E}-\mathbf{5} * \mathbf{R R}+183.803828 * \mathrm{~T}- \\
& \text { 3.2047E }-\mathbf{9} * \mathbf{R R} * \mathbf{T}-31.38 * \mathrm{~T} * \mathrm{LN}(\mathrm{T}) \\
& +364.167 \mathrm{E}+27 * \mathrm{~T} * *(-9) ; 3200 \mathrm{~N} \text { ! }
\end{aligned}
$$

Alloys

PARAMETER G(LIQUID,AG,CU;0) 298.1517384 .37 $-10.89 \mathrm{e}-\mathbf{6} * \mathbf{R R}-4.46438 * \mathrm{~T}+\mathbf{4 . 2 5 e}-\mathbf{9} * \mathbf{R R} * \mathrm{~T}$; $6000 \mathrm{~N}$ !

PARAMETER G(LIQUID,AG,CU;1) 298.15 1660.74 13.65e $-\mathbf{6} * \mathbf{R R}-2.31516 * \mathrm{~T}+7.35 \mathbf{e}-\mathbf{9} * \mathbf{R R} * \mathbf{T} ; 6000$ N!

PARAMETER G(LIQUID,AG,CU;2) 298.15 - 6.67e $\mathbf{6} * \mathbf{R R}+\mathbf{2 . 7 0 e}-\mathbf{9} * \mathbf{R R} * \mathbf{T} ; 6000 \mathrm{~N}$ !

PARAMETER G(FCC_A1,AG,CU:VA;0) 298.15 $36772.58-11.02847 * \mathrm{~T} ; 6000 \mathrm{~N}$ !

PARAMETER G(FCC_A1,AG,CU:VA;1) 298.15 $4612.43+0.28869 * \mathrm{~T} ; 6000 \mathrm{~N}$ !

\section{Conflict of Interests}

The authors declare that there is no conflict of interests regarding the publication of this paper.

\section{Acknowledgments}

Financial support of the Ministry of Education of the Czech Republic under Project LD 11046 (within COST MP0903 Action, "nanoalloys"), RVO:68081723, CEITEC-MU CZ.1.05/1.1.00/02.0068, and GA CR 108/14-12653S "stability and phase equilibria of bimetallic nanoparticles" are gratefully acknowledged. Authors thank Dr. T. Klumpler (Single Crystal X-ray Diffraction Core Facility CEITEC) for the SAXS measurements.

\section{References}

[1] C. S. S. Kumar, Metallic Nanomaterials, vol. 1, Willey-VCh, 2009.

[2] T. Mauer, N. Abdellaoui, A. Gwizda, P. M. Adam, A. Vial, and J. L. Bijeon, "Optical determination and identification of organic shell around nanoparticles: application to silvernanoparticles," Nano, vol. 8, no. 2, Article ID 1350016, 2013.

[3] S. Subramanian and J. M. Catchmark, "Control of catalytically generated electroosmotic fluid flow through surface zeta potential engineering," Journal of Physical Chemistry C, vol. 111, no. 32, pp. 11959-11964, 2007.
[4] P. Alexandridis, "Gold nanoparticle synthesis, morphology control, and stabilization facilitated by functional polymers," Chemical Engineering and Technology, vol. 34, no. 1, pp. 15-28, 2011.

[5] T. K. Sau and A. L. Rogach, "Nonspherical noble metal nanoparticles: colloid-chemical synthesis and morphology control," Advanced Materials, vol. 22, no. 16, pp. 1781-1804, 2010.

[6] H. Peng Choo, K. Y. Liew, H. Liu, C. E. Seng, W. A. K. Mahmood, and M. Bettahar, "Activity and selectivity of noble metal colloids for the hydrogenation of polyunsaturated soybean oil," Journal of Molecular Catalysis A: Chemical, vol. 191, no. 1, pp. 113-121, 2003.

[7] Y. Yuan, D. Rende, C. L. Altan, S. Bucak, and R. Ozisik, "Effect of surface modification on magnetization of iron oxide nanoparticle colloids," Langmuir, vol. 28, no. 36, pp. 1305113059, 2012.

[8] M. Sanchez-Dominguez, M. Boutonnet, and C. Solans, "A novel approach to metal and metal oxide nanoparticle synthesis: the oil-in-water microemulsion reaction method," Journal of Nanoparticle Research, vol. 11, no. 7, pp. 1823-1829, 2009.

[9] M. Oezaslan, F. Hasché, and P. Strasser, "In situ observation of bimetallic alloy nanoparticle formation and growth using hightemperature XRD," Chemistry of Materials, vol. 23, no. 8, pp. 2159-2165, 2011.

[10] J. Sopousek, J. Bursik, J. Zalesak, V. Bursikova, and P. Brož, "Interaction of silver nanopowder with copper substrate," Science of Sintering, vol. 43, no. 1, pp. 34-38, 2011.

[11] J. Sopousek, J. Bursik, J. Zalesak, and Z. Pesina, "Silver nanoparticles sintering at low temperature on a copper substrate: in situ characterisation under inert atmosphere and air," Journal of Mining and Metallurgy, Section B: Metallurgy, vol. 48, no. 1, pp. 63-71, 2012.

[12] D. G. Thompson, R. J. Stokes, R. W. Martin, P. J. Lundahl, K. Faulds, and D. Graham, "Synthesis of unique nanostructures with novel optical properties using oligonucleotide mixedmetal nanoparticle conjugates," Small, vol. 4, no. 8, pp. 10541057, 2008.

[13] J. Park and J. Lee, "Phase diagram reassessment of Ag-Au system including size effect," Calphad: Computer Coupling of Phase Diagrams and Thermochemistry, vol. 32, no. 1, pp. 135-141, 2008.

[14] J. Lee, J. Lee, T. Tanaka, and H. Mori, "In situ atomic-scale observation of melting point suppression in nanometer-sized gold particles," Nanotechnology, vol. 20, no. 47, Article ID 475706, 2009.

[15] J. Sopousek, J. Vrestal, A. Zemanova, and J. Bursik, "Phase diagram prediction and particle characterisation of $\mathrm{Sn}-\mathrm{Ag}$ nanoalloy for low melting point lead-free solders," Journal of Mining and Metallurgy B, vol. 48, no. 3, pp. 419-425, 2012.

[16] S. A. Ananthan, V. Narayanan, R. Suresh, and K. Giribabu, "Preparation and characterization of $\mathrm{Pt}$ based mono and bimetallic nano catalysis and their application of citral hydrogenation," Asian Journal of Chemistry, vol. 24, no. 2, pp. 55255529, 2012.

[17] Y. Zhang, W. Huang, S. E. Habas et al., "Near-monodisperse Ni$\mathrm{Cu}$ bimetallic nanocrystals of variable composition: controlled synthesis and catalytic activity for $\mathrm{H}_{2}$ generation," Journal of Physical Chemistry C, vol. 112, no. 32, pp. 12092-12095, 2008.

[18] J.-H. Liu, A.-Q. Wang, Y.-S. Chi, H.-P. Lin, and C.-Y. Mou, "Synergistic effect in an Au-Ag alloy nanocatalyst: CO oxidation," Journal of Physical Chemistry B, vol. 109, no. 1, pp. 40-43, 2005.

[19] G. Borkow and J. Gabbay, "Copper as a biocidal tool," Current Medicinal Chemistry, vol. 12, no. 18, pp. 2163-2175, 2005. 
[20] J. F. Sánchez-Ramírez, C. Vazquez-Lopez, and U. Pal, "Preparation and optical absorption of colloidal dispersion of $\mathrm{Au} / \mathrm{Cu}$ nanoparticles," Superficies y Vacio, vol. 15, pp. 16-18, 2002.

[21] U. Pal, J. F. Sánchez-Ramírez, L. Nolasco-Hernández, J. Mendoza-Álvarez, and J. A. Pescador-Rojas, "Synthesis and optical properties of Au-Ag alloy nanoclusters with controlled composition," Journal of Nanomaterials, vol. 2008, no. 1, Article ID 620412, 2008.

[22] M. Grzelczak, J. Pérez-Juste, P. Mulvaney, and L. M. Liz-Marzán, "Shape control in gold nanoparticle synthesis," Chemical Society Reviews, vol. 37, no. 9, pp. 1783-1791, 2008.

[23] B. Pietrobon and V. Kitaev, "Photochemical synthesis of monodisperse size-controlled silver decahedral nanoparticles and their remarkable optical properties," Chemistry of Materials, vol. 20, no. 16, pp. 5186-5190, 2008.

[24] P. M. Ossi, Disordered Materials, Springer, 2006.

[25] M. José Yacamán, J. A. Ascencio, H. B. Liu, and J. GardeaTorresdey, "Structure shape and stability of nanometric sized particles," Journal of Vacuum Science and Technology B: Microelectronics and Nanometer Structures, vol. 19, no. 4, pp. 1091-1103, 2001.

[26] J. Reyes-Gasga, S. Tehuacanero-Nunez, J. M. MontejanoCarrizales, X. Gao, and M. Jose-Yacaman, "Analysis of the contrast in icosahedral gold nanoparticles," Topics in Catalysis, vol. 46, no. 1-2, pp. 23-30, 2007.

[27] Y. Wei, S. Chen, B. Kowalczyk, S. Huda, T. P. Gray, and B. A. Grzybowski, "Synthesis of stable, low-dispersity copper nanoparticles and nanorods and their antifungal and catalytic properties," Journal of Physical Chemistry C, vol. 114, no. 37, pp. 15612-15616, 2010.

[28] R. Betancourt-Galindo, P. Y. Reyes-Rodriguez, B. A. PuenteUrbina et al., "Synthesis of copper nanoparticles by thermal decomposition and their antimicrobial properties," Journal of Nanomaterials, vol. 20, Article ID 980545, 5 pages, 2014.

[29] A. Sarkar, T. Mukherjee, and S. Kapoor, "PVP-stabilized copper nanoparticles: a reusable catalyst for "click" reaction between terminal alkynes and azides in nonaqueous solvents," Journal of Physical Chemistry C, vol. 112, no. 9, pp. 3334-3340, 2008.

[30] M. Kidwai, N. K. Mishra, V. Bansal, A. Kumar, and S. Mozumdar, "Cu-nanoparticle catalyzed O-arylation of phenols with aryl halides via Ullmann coupling," Tetrahedron Letters, vol. 48, no. 50, pp. 8883-8887, 2007.

[31] P. Singh, A. Katyal, R. Kalra, and R. Chandra, "Copper nanoparticles in an ionic liquid: an efficient catalyst for the synthesis of bis-(4-hydroxy-2-oxothiazolyl)methanes," Tetrahedron Letters, vol. 49, no. 4, pp. 727-730, 2008.

[32] N. Tamaekong, C. Liewhiran, and S. Phanichphant, "Synthesis of thermally spherical $\mathrm{CuO}$ nanoparticles," Journal of Nanomaterials, vol. 2014, Article ID 507978, 5 pages, 2014.

[33] M. Rashad, M. Rüsing, G. Berth, K. Lischka, and A. Pawlis, " $\mathrm{CuO}$ and $\mathrm{Co}_{3} \mathrm{O}_{4}$ nanoparticles: synthesis, characterizations, and raman spectroscopy," Journal of Nanomaterials, vol. 2013, Article ID 714853, 6 pages, 2013.

[34] Y.-H. Peng, C.-H. Yang, K.-T. Chen, S. R. Popuri, C.-H. Lee, and B.-S. Tang, "Study on synthesis of ultrafine $\mathrm{Cu}-\mathrm{Ag}$ core-shell powders with high electrical Conductivity," Applied Surface Science, vol. 263, no. 15, pp. 38-44, 2012.

[35] M. Tsuji, M. Matsunaga, H. Kumagai et al., "Synthesis of Au@ Ag@Cu trimetallic nanocrystals using three-step reduction," CrystEngComm, vol. 15, pp. 1345-1351, 2013.
[36] J. P. Hajra and S. Acharya, "Thermodynamics and phase equilib-ria involving nano phases in the Cu-Ag system," Journal of Nanoscience and Nanotechnology, vol. 4, no. 7, pp. 899-906, 2004.

[37] G. Garzel, J. Janczak-Rusch, and L. Zabdyr, "Reassessment of the Ag-Cu phase diagram for nanosystems including particle size and shape effect," Calphad: Computer Coupling of Phase Diagrams and Thermochemistry, vol. 36, pp. 52-56, 2012.

[38] P. Broz, J. Sopousek, J. Vrestal, and J. Pinkas, "Combination of thermal analysis and knudsen effusion mass spectrometry for study of metal materials on macro- and nano-scale," ECS Transactions, vol. 46, no. 1, pp. 69-76, 2013.

[39] NETZSCH, Termische Analyse, Instument Manual, Supplementary Information for Calibration Set 6.223.5-91.3, 1998.

[40] A. Dinsdale, A. Watson, A. Kroupa, J. Vrestal, A. Zemanova, and J. Vizdal, "Atlas of phase diagrams for lead/free soldering," COST 531, vol. 1, 2009.

[41] A. T. Dinsdale, "SGTE data for pure elements," Calphad, vol. 15, no. 4, pp. 317-425, 1991.

[42] J. Lee, J. Park, and T. Tanaka, "Effects of interaction parameters and melting points of pure metals on the phase diagrams of the binary alloy nanoparticle systems: A classical approach based on the regular solution model," Calphad, vol. 33, no. 2, pp. 377-381, 2009.

[43] J. A. V. Butler, "The Thermodynamics of the Surfaces of Solutions," Proceedings of the Royal Society A, vol. 135, pp. 348-375, 1932.

[44] R. Picha, J. Vřešt'ál, and A. Kroupa, "Prediction of alloy surface tension using a thermodynamic database," Calphad, vol. 28, no. 2, pp. 141-146, 2004.

[45] J. Sopousek, J. Vrestal, J. Pinkas et al., "Cu-Ni nanoalloy phase diagram-prediction and experiment," Calphad: Computer Coupling of Phase Diagrams and Thermochemistry, vol. 45, pp. 33-39, 2014.

[46] ThermoCalc software, 2014, http://www.thermocalc.com/.

[47] J. Lee, W. Shimoda, and T. Tanaka, "Surface tension and its temperature coefficient of liquid $\mathrm{Sn}-\mathrm{X}(\mathrm{X}=\mathrm{Ag}, \mathrm{Cu})$ alloys," Materials Transactions, vol. 45, no. 9, pp. 2864-2870, 2004.

[48] G. Lang, P. Laty, J. C. Joud, and P. Desre, "Measurement of the surface tension of several pure liquid metals by different methods," Zeitschrift fuer Metallkunde/Materials Research and Advanced Techniques, vol. 68, no. 2, pp. 113-116, 1977.

[49] P. D. Ownby and J. Lui, "Surface-ebnergy of liquid copper and single-crystal sapphire and the wetting behaviour of copper on sapphire," Journal of Adhesion Science and Technology, vol. 2, no. 4, pp. 255-269, 1988.

[50] K. Nogi, K. Oishi, and K. Ogino, "Wettability of solid oxides by liquid pure metals," Materials Transactions, JIM, vol. 30, no. 2, pp. 137-145, 1989.

[51] R. F. Brooks, I. Egry, S. Seetharaman, and D. Grant, "Reliable data for high-temperature viscosity and surface tension: results from a European project," High Temperatures-High Pressures, vol. 33, no. 6, pp. 631-637, 2001.

[52] T. Iida and R. I. L. Guthrie, The Physical Properties of Liquid Metals, Oxford Science Publications, 1993.

[53] A. Shirinyan, M. Wautelet, and Y. Belogorodsky, "Solubility diagram of the $\mathrm{Cu}-\mathrm{Ni}$ nanosystem," Journal of Physics Condensed Matter, vol. 18, no. 8, pp. 2537-2551, 2006.

[54] G. Lohöfer, J. Brillo, and I. Egry, "Thermophysical properties of undercooled liquid $\mathrm{Cu}-\mathrm{Ni}$ alloys," International Journal of Thermophysics, vol. 25, no. 5, pp. 1535-1550, 2004. 

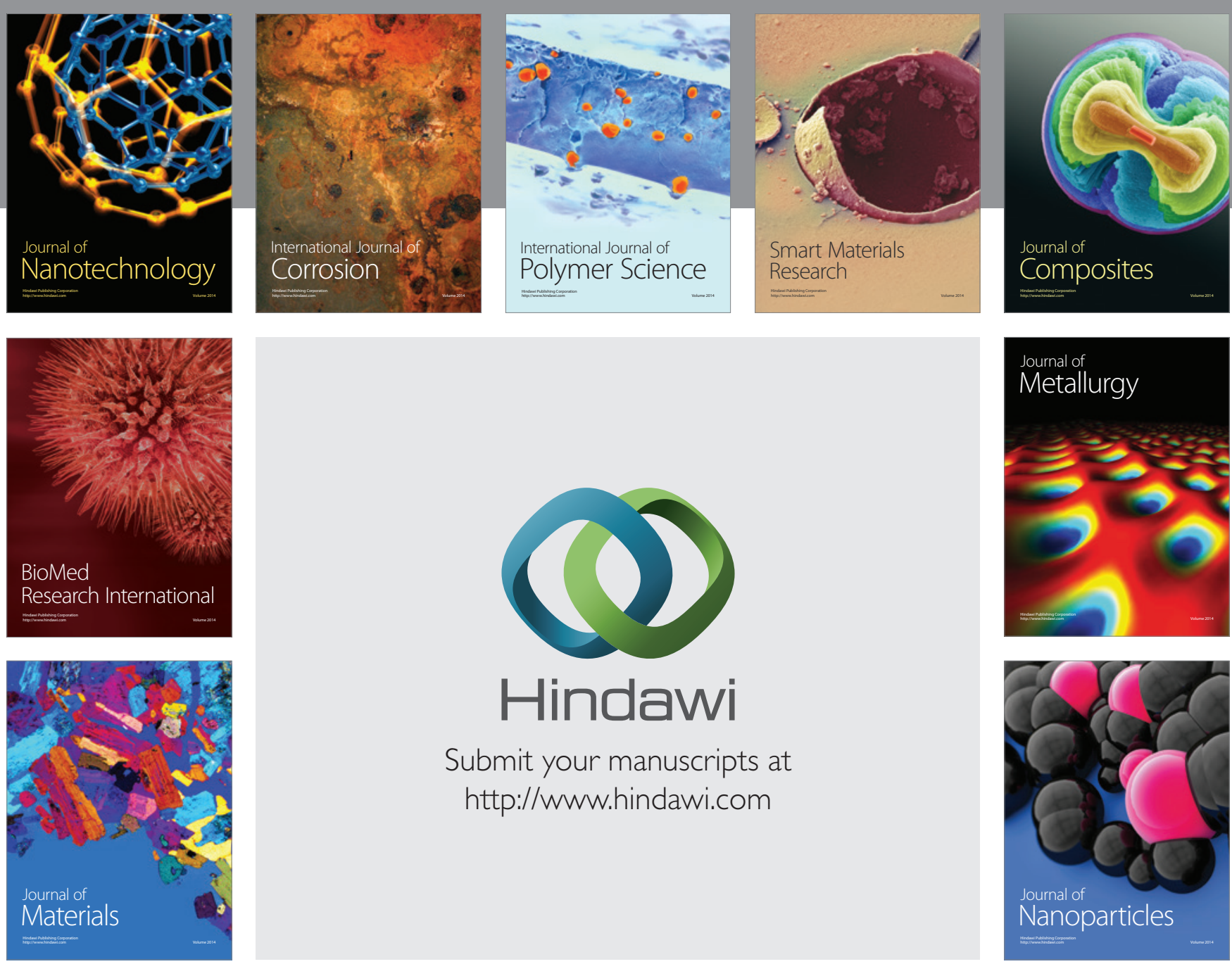

Submit your manuscripts at http://www.hindawi.com
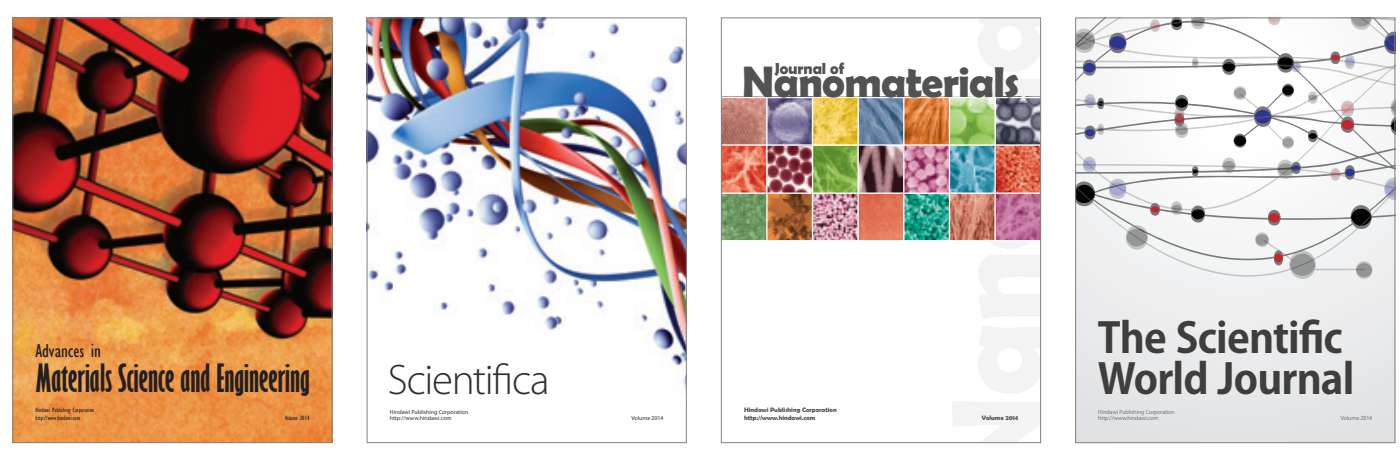

\section{The Scientific World Journal}
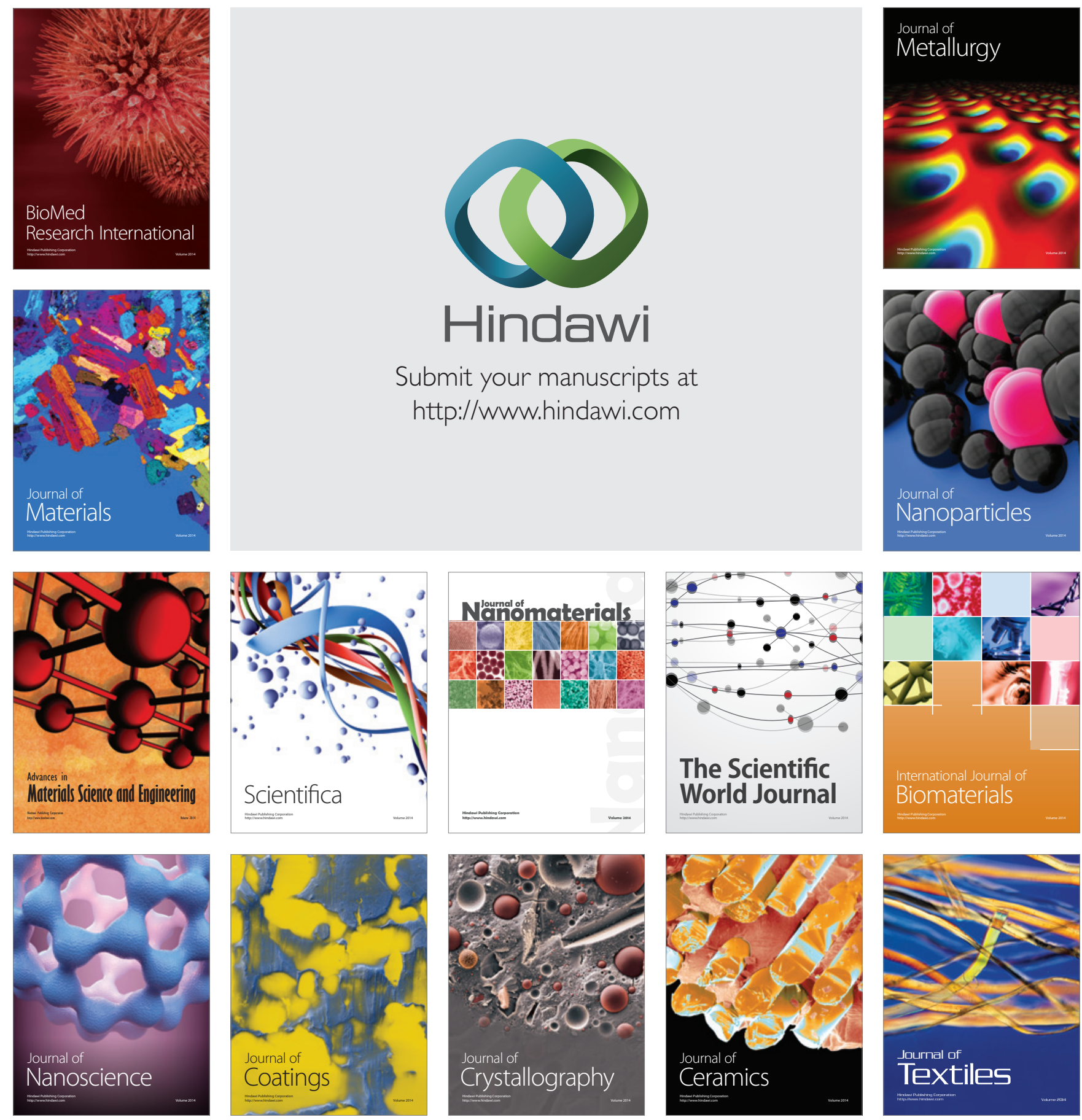